\title{
Variability and trends in total and vertically resolved stratospheric ozone based on the CATO ozone data set
}

\author{
D. Brunner ${ }^{1,{ }^{*}}$, J. Staehelin ${ }^{1}$, J. A. Maeder ${ }^{1}$, I. Wohltmann ${ }^{2}$, and G. E. Bodeker ${ }^{3}$ \\ ${ }^{1}$ Institute for Atmospheric and Climate Science, ETH Zurich, Switzerland \\ ${ }^{2}$ Alfred Wegner Institute, Potsdam, Germany \\ ${ }^{3}$ National Institute of Water and Atmospheric Research (NIWA), New Zealand \\ *now at: Empa, Swiss Federal Laboratories for Materials Testing and Research, Dübendorf, Switzerland
}

Received: 22 June 2006 - Published in Atmos. Chem. Phys. Discuss.: 12 July 2006

Revised: 25 October 2006 - Accepted: 27 October 2006 - Published: 31 October 2006

\begin{abstract}
Trends in ozone columns and vertical distributions were calculated for the period 1979-2004 based on the ozone data set CATO (Candidoz Assimilated Three-dimensional Ozone) using a multiple linear regression model. CATO has been reconstructed from TOMS, GOME and SBUV total column ozone observations in an equivalent latitude and potential temperature framework and offers a pole to pole coverage of the stratosphere on 15 potential temperature levels. The regression model includes explanatory variables describing the influence of the quasi-biennial oscillation (QBO), volcanic eruptions, the solar cycle, the Brewer-Dobson circulation, Arctic ozone depletion, and the increase in stratospheric chlorine. The effects of displacements of the polar vortex and jet streams due to planetary waves, which may significantly affect trends at a given geographical latitude, are eliminated in the equivalent latitude framework. The QBO shows a strong signal throughout most of the lower stratosphere with peak amplitudes in the tropics of the order of $10-20 \%$ (peak to valley). The eruption of Pinatubo led to annual mean ozone reductions of $15-25 \%$ between the tropopause and $23 \mathrm{~km}$ in northern mid-latitudes and to similar percentage changes in the southern hemisphere but concentrated at altitudes below $17 \mathrm{~km}$. Stratospheric ozone is elevated over a broad latitude range by up to 5\% during solar maximum compared to solar minimum, the largest increase being observed around $30 \mathrm{~km}$. This is at a lower altitude than reported previously, and no negative signal is found in the tropical lower stratosphere. The Brewer-Dobson circulation shows a dominant contribution to interannual variability at both high and low latitudes and accounts for some of the ozone increase seen in the northern hemisphere since the mid-1990s. Arctic ozone depletion significantly affects the high northern latitudes between January and March and ex-
\end{abstract}

Correspondence to: D. Brunner

(dominik.brunner@empa.ch) tends its influence to the mid-latitudes during later months. The vertical distribution of the ozone trend shows distinct negative trends at about $18 \mathrm{~km}$ in the lower stratosphere with largest declines over the poles, and above $35 \mathrm{~km}$ in the upper stratosphere. A narrow band of large negative trends extends into the tropical lower stratosphere. Assuming that the observed negative trend before 1995 continued to 2004 cannot explain the ozone changes since 1996. A model accounting for recent changes in equivalent effective stratospheric chlorine, aerosols and Eliassen-Palm flux, on the other hand, closely tracks ozone changes since 1995.

\section{Introduction}

Anthropogenic stratospheric ozone depletion has been discussed since the early 1970s (Crutzen, 1970; Johnston, 1971; Molina and Rowland, 1974; Stolarski and Cicerone, 1974). In 1985 the Antarctic ozone hole was detected (Farman et al., 1985) and in 1988 significant winter time decreases were first documented for northern mid-latitudes from ground-based measurements and later confirmed by satellite observations (Stolarski et al., 1991). Polar and mid-latitude trends were subsequently reported in many studies. For an overview see Staehelin et al. (2001); World Meteorological Organization (2003).

During the 1990s a number of studies provided evidence that part of the observed trends can be attributed to processes other than anthropogenic ozone depletion. Such processes included decadal scale climate variability related to the North Atlantic Oscillation (NAO) or Arctic Oscillation (e.g. Appenzeller et al., 2000), tropopause altitude (Steinbrecht et al., 1998), and changes in the strength of the Brewer-Dobson circulation (Fusco and Salby, 1999; Hadjinicolaou et al., 2002). These factors were found to affect the trends in addition to

Published by Copernicus GmbH on behalf of the European Geosciences Union. 
the solar cycle, the quasi-biennial oscillation (QBO) and volcanic eruptions which had been appreciated already in previous assessments of stratospheric ozone depletion (World Meteorological Organization, 1995).

As consequence of the Montreal Protocol and its amendments the emissions of anthropogenic ozone depleting substances (ODSs) decreased. According to the temporal evolution of ODSs in the stratosphere, chemical ozone depletion probably reached a maximum around the late 1990s and slowly decreased thereafter. Therefore, the discussion started whether the effect of the Montreal Protocol on the ozone layer can already be identified in the present observations (Weatherhead et al., 2000; Reinsel et al., 2002; Weatherhead and Andersen, 2006). Newchurch et al. (2003) reported on first signs of recovery analyzing upper stratospheric ozone trends while Reinsel et al. (2005) reported that the linear trend in total column ozone had changed significantly beyond 1996 poleward of $40^{\circ}$. Identifying ozone recovery requires both detection of a positive change in ozone tendency as well as attribution of that change to decreasing ODSs. Questions remain whether all other factors influencing ozone such as solar cycle or planetary wave forcing were properly accounted for in these studies (Steinbrecht et al., 2004; Dhomse et al., 2006). An important problem in all trend studies using satellite data arises from the fact that the ozone time series available for fitting a statistical model are relatively short in comparison to the timescales of variability of some of the explanatory variables. This is additionally complicated by correlations among these variables which limits our ability to separate different effects (Solomon et al., 1996; Salby et al., 1997). Extending the time series out to 2004 now allows for a better separation between solar cycle, volcanic eruptions and QBO effects. Unlike the previous two solar cycles the latest one (no. 23) was not synchronized with a major volcanic eruption and the QBO was in opposite phase during solar maximum than previously.

In this study we present the results of a multiple linear regression analysis applied to the quasi-3-D ozone data set CATO (CANDIDOZ Assimilated Three-dimensional Ozone; CANDIDOZ is the EU project "Chemical and Dynamical Influences on Decadal Ozone Change") (Brunner et al., 2006). In CATO the stratospheric ozone distribution is represented in an equivalent latitude - potential temperature coordinate system which has the advantage that it closely follows the contours of a passive tracer which are distorted by planetary waves (Schoeberl et al., 1989). Sharp gradients e.g. across the edge of the polar vortex are much better preserved in this coordinate system than in a standard zonal mean view (Bodeker et al., 2001). In addition, an important part of dynamical variability associated with planetary waves and meridional displacements of the vortex is efficiently removed in this framework. These effects not only account for a large fraction of the variability in total ozone observations but also contribute to long-term trends in a given geographical lat- itude band as demonstrated by Wohltmann et al. $(2006)^{1}$. Since CATO was reconstructed from satellite total ozone measurements it provides a unique view of the vertical distribution of stratospheric ozone that is fully consistent with the total columns. It extends from pole to pole and currently covers the period 1979 to 2004 without gaps.

So far only few satellite-based studies are available on long-term ozone trends in the lower stratosphere where the bulk of ozone resides. However, knowledge of the vertical distribution of the trends is essential as it provides additional insight into the processes governing stratospheric ozone. Most previous studies were restricted to altitudes higher than $20 \mathrm{~km}$ due to limitations in profile retrievals from SAGE (particularly SAGE I) and SBUV which were additionally complicated during periods of enhanced volcanic aerosol. Wang et al. (2002) presented an improved algorithm for SAGE II retrievals below $20 \mathrm{~km}$ which allowed calculating ozone trends down to the tropopause for the period 1984 to 1999 . In an earlier study by Randel and Wu (1999) total column data from TOMS were combined with SAGE I/II profile data to calculate the residual amount between the tropopause and $20 \mathrm{~km}$ altitude. The present study complements these analyzes as it is based on a completely independent data set which is more complete in terms of temporal and spatial coverage.

Section 2.1 presents an overview of the CATO data set including a comparison of time series at different levels in the stratosphere with independent observations. CATO has been described in detail in Brunner et al. (2006). The statistical model is described in Sect. 2.2. Results of the regression analysis are then shown in Sect. 3 both for total ozone and the corresponding vertical distribution. We highlight the influence of the QBO, solar cycle, volcanic eruptions, planetary wave forcing, and polar ozone depletion, and analyze the trend attributable to the anthropogenic release of ODSs. Finally, in Sect. 3.3 we study the recent evolution of ozone and show that since 1996 there has been a statistically significant change in ozone trend. By using the regression model to attribute these recent changes to the explanatory variables included in the model, we show to what extent these changes result from changes in stratospheric ODSs concentrations and hence to what extent these changes can be interpreted as a sign of ozone recovery.

\section{Data and methods}

\subsection{Reconstructed ozone data set CATO}

CATO is a statistically reconstructed data set describing the vertical distribution of ozone in the stratosphere and the horizontal distribution of residual ozone columns in the tropo-

\footnotetext{
${ }^{1}$ Wohltmann, I., Lehmann, R., Rex, M., Brunner, D., and Mäder, J. A.: A process-oriented regression model for column ozone, J. Geophys. Res., submitted, 2006.
} 
(a) Mid-latitude anomalies at $40 \mathrm{hPa} / 22 \mathrm{~km}$

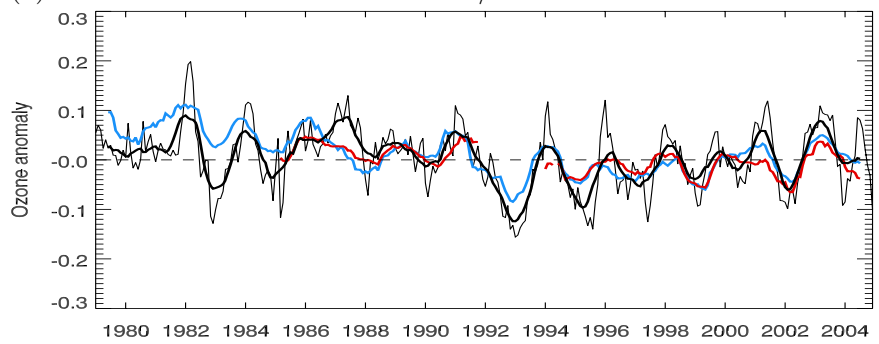

(b) Mid-latitude anomalies at $120 \mathrm{hPa} / 15 \mathrm{~km}$

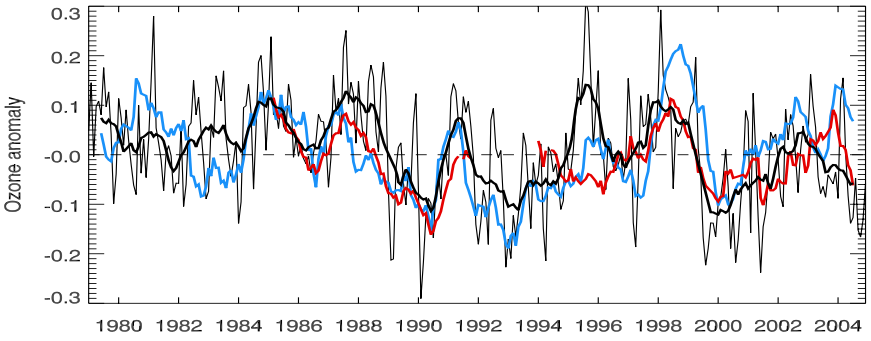

(c) Tropical anomalies at $30 \mathrm{hPa} / 24 \mathrm{~km}$

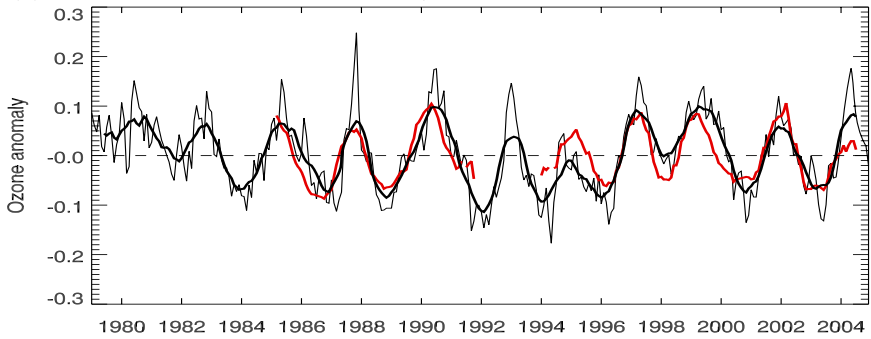

Fig. 1. Time series of normalized monthly ozone anomalies (with respect to the 1985-2004 monthly means) from CATO, Payerne ozonesondes, and SAGE-II. The thin black lines are the CATO monthly mean anomalies, the thick black lines are 12-month running means through these data. For Payerne (blue) and SAGE-II (red) only the running means are shown. Panels (a) and (b) are for northern mid-latitudes. Here, CATO data are mean values over $42^{\circ}$ to $48^{\circ} \mathrm{N}$ equivalent latitude. SAGE-II are averages over $40^{\circ}$ to $50^{\circ} \mathrm{N}$ geographical latitude. The station Payerne, Switzerland, is at $47^{\circ} \mathrm{N}$. (a) Anomalies at $40 \mathrm{hPa}$ (SAGE-II data at $22 \mathrm{~km}$ ). (b) Anomalies at $120 \mathrm{hPa}$ (SAGE-II at $15 \mathrm{~km}$ ). (c) Tropical anomalies at $30 \mathrm{hPa}$ (SAGE-II at $24 \mathrm{~km}$ ). Here, both CATO and SAGE-II data are $6^{\circ} \mathrm{S}$ to $6^{\circ} \mathrm{N}$ averages.

sphere. It currently covers the period January 1979 to December 2004. The tropospheric columns are represented in geographical longitude $(\lambda)$ and latitude $(\phi)$ (with $10^{\circ} \times 6^{\circ}$ resolution) and the stratospheric distribution in equivalent latitude $\left(\phi_{E}\right)$ and potential temperature $(\theta)$ coordinates $\left(6^{\circ}\right.$ horizontal resolution and 15 potential temperature levels between $326 \mathrm{~K}$ and $1445 \mathrm{~K}$ ). The reconstruction is based on combining satellite total ozone observations with meteorological information on short-term meridional excursions of air masses due to isentropic transport using a data assimilation approach. The method is described in detail in Brunner et al. (2006).

In that paper it was shown that CATO agrees reasonably well with observations from ozonesondes and HALOE including a realistic description of seasonal and interannual variability. Significant deviations from observed profiles were found at high polar latitudes as well as in the tropical lower stratosphere. However, these comparisons only covered data from a few years and therefore did not provide any evidence that CATO is able to reproduce actual changes in vertical ozone over the whole time period. Figure 1 therefore compares time series of deseasonalized and normalized (with respect to the 1985-2004 monthly means) monthly ozone anomalies from CATO with the corresponding anomalies from a selected ozonesonde station (Payerne, Switzerland, $47^{\circ} \mathrm{N}, 7^{\circ} \mathrm{E}$ ) and from the Stratospheric Aerosol and Gas Experiment SAGE-II (version 6.2) (Wang et al., 2002). For SAGE-II (thick red lines) and Payerne (thick blue) only 12 -month running means are shown for better visibility. For CATO (thick black), additionally the individual monthly anomalies are presented (thin black). SAGE-II data during the first three years after eruption of Mount Pinatubo in June 1991 were affected by the enhanced volcanic aerosol and therefore excluded. Note that CATO data are mean values for a given equivalent latitude band whereas SAGE-II are zonal means in geographical coordinates. 
In northern mid-latitudes at $40 \mathrm{hPa}$ (Fig. 1a) the variability is dominated by the QBO which has a somewhat larger amplitude in CATO than in the other data sets. Some difference between CATO and SAGE-II is to be expected due to the use of different vertical coordinate systems (pressure levels vs. geometric altitude). Overall, there is a reasonable agreement in particular with respect to the timing and variations in amplitude of the QBO. With respect to long-term trends, however, there are clear differences. CATO anomalies tend to be a few percent below Payerne during the early 1980s but somewhat above in the latest years. CATO exhibits the largest increase after 1992 and generally the lowest decrease over the whole period. Only $2 \mathrm{~km}$ higher at $30 \mathrm{hPa}$ (not shown), however, CATO exhibits a somewhat larger decrease than SAGE-II and Payerne apparently compensating for the too small negative tendency at $40 \mathrm{hPa}$. This seems to be an artifact of the reconstruction method which is also evident from Fig. 9 presented later.

In the lowermost stratosphere at $120 \mathrm{hPa}$ (Fig. 1b) the variability is very large in all data sets and the overall evolution of CATO is in good agreement with SAGE-II. A notable exception is seen around 1996 where CATO shows a large positive anomaly not observed in the other data sets. Even though a similar positive anomaly is observed in other ozonesonde data (for instance at Sapporo, Japan), a detailed comparison with a number of sonde stations and at different altitudes points to generally larger deviations during this period. Most likely this is due to the assimilation of GOME data between August 1995 and June 1996 when no TOMS data were available. Assimilation of GOME observations was performed in a non-optimal way as already noticed in Brunner et al. (2006) (see their Fig. 7). Given these findings, the period August 1995 to June 1996 was excluded from all regression analyzes even though this has very little effect on the results. Significant differences are also seen between CATO and Payerne in the early 1980s, but differences between Payerne and the nearby station Hohenpeissenberg are of similar magnitude during this period (not shown).

The lowest panel (Fig. 1c) compares CATO and SAGE-II at $30 \mathrm{hPa}$ in the tropics, where the signal is largely dominated by the QBO. There is very good agreement between both data sets except for the period 1995/96 when GOME data were assimilated.

Meteorological fields required for the reconstruction include pressure, temperature and potential vorticity which were obtained from ERA-40 reanalyses (Uppala et al., 2005) up to August 2002 and from operational analyses of the European Center for Medium Range Weather Forecasts (ECMWF) thereafter. Errors in ERA-40 (potential) temperature trends would affect trends in CATO ozone values. Large and variable biases have been identified in ERA-40 temperatures in the upper stratosphere (Uppala et al., 2005). Below $10 \mathrm{hPa}$ (about $30 \mathrm{~km}$ ), however, which is the main focus of this study, ERA-40 temperatures are considered to be generally of high quality (Randel et al., 2005) and to show realistic long-term trends (Santer et al., 2004; Labitzke and Kunze, 2005). Some problems with a potential impact on the CATO results have been identified over the polar regions including an erroneous positive trend in late autumn/early winter (October-January) temperatures at $30 \mathrm{hPa}$ between 1979 and 2001 (Labitzke and Kunze, 2005), and an unrealistic vertically oscillating structure during winter and spring months (Karpetchko et al., 2005). Overall, we thus do not expect large biases in the long-term performance of CATO introduced by the meteorological data, but a firm conclusion can not be drawn at this stage without a thorough sensitivity study. The ERA-40 reanalysis is also known to produce a too strong Brewer-Dobson circulation in the stratosphere. However, the CATO reconstruction method does not make use of the noisy and problematic vertical winds thus avoiding these problems as already noted in Brunner et al. (2006).

An important advantage of CATO is that it has a pole to pole coverage and spans the complete period 1979 to 2004 including the months following the eruption of Mount Pinatubo. Moreover, CATO is based on the carefully homogenized NIWA assimilated total ozone data base where observations from the series of TOMS, GOME and SBUV instruments are combined into a single homogeneous data set by correcting for biases with respect to ground-based Dobson stations and for biases between satellite instruments observed during periods of overlap (Bodeker et al., 2001, 2005).

Because the reconstruction method is based on the assumption that ozone behaves like a passive tracer on time scales of short-term meridional excursions, it fails to produce a realistic distribution above about $30 \mathrm{~km}$ altitude where the chemical lifetime becomes short. Therefore, CATO is relaxed towards the monthly mean climatology of Fortuin and Kelder (1998) on isentropes higher than $820 \mathrm{~K}$ with a relaxation timescale decreasing from 70 days at $820 \mathrm{~K}$ to 2.5 days at $1445 \mathrm{~K}$. As a consequence, any variability above $820 \mathrm{~K}$ is damped. We have therefore created a second data set where the relaxation above $820 \mathrm{~K}$ was replaced by the assimilation of vertical profiles from the merged SBUV and SBUV/2 version 8 data (see Brunner et al., 2006). The SBUV record at $35-40 \mathrm{~km}$ altitude shows a drift relative to SAGE of about $2 \% /$ decade and an upward shift by about 3\% from 1995 to 1998 probably due to satellite intercalibration issues (Steinbrecht et al., 2006). This second CATO version is only used for sensitivity checks and for the interpretation of variability and trends above $30 \mathrm{~km}$ altitude. Note that the two versions differ slightly in their vertical distribution whereas the total columns are basically identical because of the assimilation of total column observations.

CATO has been used by Wohltmann et al. (2005) to reconstruct an "integrated equivalent latitude proxy" for individual Dobson stations for use in regression analysis of long-term ozone trends. The station-specific proxy time series were obtained by vertically integrating the 1979-2004 mean CATO ozone field $\chi_{\text {clim }}\left(\phi_{E}, \theta\right)$ along the equivalent latitude profiles $\phi_{E}(\lambda, \phi, \theta)$ calculated at each measurement point and time. 
Wohltmann et al. (2006) ${ }^{1}$ demonstrated that this proxy is able to explain a large part of total ozone variability measured at these stations.

\subsection{Regression model}

The set of explanatory variables (or proxies) chosen for the regression model describes the influence of the solar cycle, the QBO, stratospheric aerosol loading following volcanic eruptions, the strength of the Brewer-Dobson circulation, and the anthropogenic impact on ozone through release of ozone depleting substances (ODSs). A linear response of ozone to changes in these variables is assumed though the response is allowed to be different for different months of the year. The proxies are selected to model as closely as possible the most relevant processes influencing stratospheric ozone variability. A more detailed motivation for the choice of variables we use here is given in the companion paper by Wohltmann et al. (2006) ${ }^{1}$. Note that in contrast to other trend studies the influence of various climate modes such as NAO or the El Niño - Southern Oscillation are not included explicitly. NAO and other climate modes may change the position of troughs and ridges of planetary waves and hence modulate the altitude of the tropopause (Appenzeller et al., 2000; Weiss et al., 2001) and invoke meridional advection of ozone from regions of higher or lower climatological mean concentrations (Koch et al., 2002). While this may explain a significant fraction of ozone variability at a given point on the globe, much of these effects are eliminated when adopting an equivalent latitude and potential temperature framework (cf. Wohltmann et al., 2005) which is the approach followed here. In addition, NAO influences the propagation of waves into the stratosphere and hence the deposition of wave momentum driving the Brewer-Dobson circulation (Rind et al., 2005). This further affects the polar vortex which is stronger when the NAO is in a positive phase (Schnadt and Dameris, 2003). These effects are again accounted for, at least qualitatively, by including Eliassen-Palm (EP) flux as a proxy for the Brewer-Dobson circulation (Fusco and Salby, 1999) and the volume of polar stratospheric clouds (PSC) to describe Arctic ozone loss (Rex et al., 2004). The setup of the regression model is similar to that by Stolarski et al. (1991) or Ziemke et al. (1997) and is formulated in one of the two following forms

$$
\begin{aligned}
& Y(t)=a+b \cdot \operatorname{EESC}(t)+\sum_{j=1}^{N} c_{j} \cdot X_{j}(t)+\epsilon(t) \\
& Y(t)=a+b \cdot t+\sum_{j=1}^{N} c_{j} \cdot X_{j}(t)+\epsilon(t)
\end{aligned}
$$

$\operatorname{EESC}(t)$ : time series of equivalent effective stratospheric chlorine

$t$ : number of months since start of record $(t=1$ for January 1979), used in alternative model instead of EESC.

$Y(t)$ : target variable, monthly mean total ozone column or ozone partial pressure in month $t$

$a$ : seasonally varying intercept (offset) of the ozone time series

$b: \quad$ seasonally varying EESC or trend coefficient

$X_{j}(t)$ : time series of explanatory variable $j(j=1, \ldots, N)$

$c_{j}$ : seasonally varying coefficients describing the influence of explanatory variable $j$

$N$ : Number of explanatory variables in addition to seasonal offset and trend components

$\epsilon(t)$ : residual variations not described by the model

Unless we only consider annual mean effects, the regression coefficients $a, b$ and $c_{j}$ are allowed to depend on the month of the year. This time dependence is modelled by 12 month and 6-month sine and cosine harmonic series. The time dependence of the coefficients $c_{j}$ is thus given by

$$
\begin{array}{r}
c_{j}(t)=c_{j, 1}+\sum_{k=1}^{2}\left[\begin{array}{c}
c_{j, 2 k} \cdot \cos (2 \pi k t / 12)+ \\
\left.c_{j, 2 k+1} \cdot \sin (2 \pi k t / 12)\right]
\end{array}\right.
\end{array}
$$

and the same formula is applied to coefficients $a$ and $b$. Thus, usually 5 coefficients need to be estimated for a single proxy time series to account for the fact that the response of ozone to changes in the proxy may vary with season. Because of the small seasonal variation that was found for the influence of solar effects, only 3 coefficients were used to represent the solar cycle.

The linear regression model was applied to (i) time series of monthly mean total ozone at 30 discrete equivalent latitudes (at $6^{\circ}$ resolution) and (ii) to monthly mean stratospheric ozone fields as a function of equivalent latitude (same resolution as total ozone) and pressure. For the latter the CATO fields were interpolated from the native 15 isentropic levels onto 14 discrete pressure levels $(190,120,90,60,40$, $30,20,15,10,7,5,3.5,2.5,1.5 \mathrm{hPa})$. Because stratospheric temperatures have a trend on their own, ozone trends on isentropes are not identical to trends on pressure levels. We prefer the representation on pressure levels to be compatible with other trend studies. For the analysis of vertical ozone variability only annual mean effects are usually considered here. In this case no harmonic expansion is applied except to the seasonal offset $a$.

Table 1 lists the different explanatory variables together with the source of the data and Fig. 2 shows the individual time series. All proxy data have been developed or collected as part of the EU project CANDIDOZ. Table 2 additionally shows some characteristic values of the proxies. These include standard deviations as well as maximum and minimum values and linear trends for different periods, all normalized by the standard deviation. The anthropogenic influence is represented by equivalent effective stratospheric chlorine (EESC) as used in (World Meteorological Organization, 
Table 1. List of explanatory variables used in the regression model. Copies of these proxy data sets can be obtained from http://fmiarc.fmi. fi/candidoz/proxies.html.

\begin{tabular}{|c|c|c|}
\hline Proxy & Description & Source \\
\hline SOLAR & $\mathrm{Mg}$ II index (core to wing ratio) & $\begin{array}{l}\text { http://www.iup.physik.uni-bremen.de/gome/ } \\
\text { gomemgii.html }\end{array}$ \\
\hline QBO10 & $\mathrm{QBO}$ at $10 \mathrm{hPa}$ measured at Singapore & Courtesy of B. Naujokat (FU Berlin) \\
\hline QBO30 & QBO at $30 \mathrm{hPa}$ measured at Singapore & Courtesy of B. Naujokat (FU Berlin) \\
\hline AERO & $\begin{array}{l}\text { Volcanic aerosols, vertically integrated } \\
\text { aerosol surface area per unit surface }\end{array}$ & $\begin{array}{l}\text { SPARC Stratospheric Aerosol Assessment } \\
\text { http://www-sparc.larc.nasa.gov/ }\end{array}$ \\
\hline EPFLUX & $\begin{array}{l}\text { Vertical component of EP flux at } 100 \mathrm{hPa} \\
\text { averaged over } 45^{\circ}-75^{\circ} \text { north and south }\end{array}$ & $\begin{array}{l}\text { NCEP data processed by AWI Potsdam, } \\
\text { http://www.awi-potsdam.de/www-pot/atmo/ } \\
\text { candidoz/ }\end{array}$ \\
\hline EESC & Equivalent effective stratospheric chlorine & $\begin{array}{l}\text { Europ. } \quad \text { Environ. Agency, http: } \\
\text { //dataservice.eea.eu.int/dataservice/viewdata/ } \\
\text { viewtbl.asp?id=52\&i=1\&res=3 }\end{array}$ \\
\hline VPSC & $\begin{array}{l}\text { PSC volume in northern hemisphere } \\
\text { multiplied by EESC }\end{array}$ & $\begin{array}{l}\text { NCEP data processed by AWI Potsdam, } \\
\text { http://www.awi-potsdam.de/www-pot/atmo/ } \\
\text { candidoz/ }\end{array}$ \\
\hline
\end{tabular}

Table 2. Statistics of the monthly values of the explanatory variables for the period 1979-2004, and linear trend fits for three selected periods. For better comparison minimum, maximum and trends were normalized by the standard deviation, i.e. they were computed from the time series (proxy $-\overline{\text { proxy }}) / \sigma$ (proxy). For some variables different time series were used for the northern $(-\mathrm{N})$ and southern $(-\mathrm{S})$ hemisphere.

\begin{tabular}{|c|c|c|c|c|c|c|c|c|c|}
\hline Proxy & $1 \sigma$ & Min & Max & $\begin{array}{r}\text { Trend/dec } \\
1979-1995\end{array}$ & Sig 1 & $\begin{array}{r}\text { Trend/dec } \\
1979-2004\end{array}$ & Sig & $\begin{array}{r}\text { Trend/dec } \\
1996-2004\end{array}$ & Sig \\
\hline SOLAR & 512 & -1.36 & 2.12 & -0.69 & $* * *$ & -0.21 & $* *$ & 1.42 & $* * *$ \\
\hline QBO10 & $19.3 \mathrm{~m} / \mathrm{s}$ & -1.60 & 1.67 & -0.06 & & 0.09 & & 0.24 & \\
\hline QBO30 & $18.1 \mathrm{~m} / \mathrm{s}$ & -1.56 & 1.38 & 0.12 & & 0.04 & & 0.56 & \\
\hline AERO-N & $3.28 \times 10^{6} \mu \mathrm{m}^{2} \mathrm{~cm}^{-2}$ & -0.66 & 4.56 & 0.76 & $* * *$ & -0.17 & $*$ & -0.06 & $* * *$ \\
\hline AERO-S & $3.70 \times 10^{6} \mu \mathrm{m}^{2} \mathrm{~cm}^{-2}$ & -0.68 & 4.76 & 0.92 & $* * *$ & -0.13 & . & -0.13 & $* * *$ \\
\hline EESC & $476 \mathrm{ppt}$ & -2.09 & 1.08 & 1.87 & $* * *$ & 1.23 & $* * *$ & -0.52 & $* * *$ \\
\hline EPFLUX-N ${ }^{2}$ & $2.6 \times 10^{4} \mathrm{~kg} \mathrm{~s}^{-2}$ & -2.49 & 2.06 & 0.39 & * & 0.27 & $* * *$ & 1.52 & $* * *$ \\
\hline EPFLUX-S ${ }^{2}$ & $2.2 \times 10^{4} \mathrm{~kg} \mathrm{~s}^{-2}$ & -2.00 & 2.12 & 1.12 & $* * *$ & 0.80 & $* * *$ & 0.58 & \\
\hline VPSC-N ${ }^{2}$ & $1.2 \times 10^{20} \mathrm{~m}^{3} \mathrm{ppt}$ & -0.96 & 3.06 & 0.57 & $* * *$ & 0.36 & $* * *$ & -2.40 & $* * *$ \\
\hline VPSC-S ${ }^{2}$ & $6.6 \times 10^{20} \mathrm{~m}^{3} \mathrm{ppt}$ & -1.63 & 1.56 & 1.47 & $* * *$ & 1.07 & $* * *$ & -1.48 & $* * *$ \\
\hline
\end{tabular}

${ }^{1}$ Significance of trend (p-values): $0{ }^{\prime} * * *{ }^{\prime} 0.0011^{*} *{ }^{\prime} 0.01{ }^{*}{ }^{\prime}, 0.05, \cdot 0.1$. Thus one or more stars indicates value is significant at $95 \%$ level. ${ }^{2}$ Numbers only refer to March values in the northern hemisphere and to September values in the southern hemisphere when the accumulated proxies reach their maximum.

2003), or alternatively by a linear trend. EESC is a measure of ozone depleting stratospheric chlorine and bromine levels estimated from ground-based measurements of halocarbons with assumptions on an average transit time from the surface into the stratosphere of 3 years and on rates at which halocarbons are destroyed in the stratosphere. As noted by Newman et al. (2006), EESC as used here is representative for the midlatitude lower stratosphere but not for the polar stratosphere where transit times of the order 5 to 6 years would be more appropriate.
In order to represent the influence of the 11-year solar cycle we use the Mg II solar index as suggested by Viereck et al. (2001) since it best describes the variability in solar UV output.

QBO is another proxy that has been traditionally included in ozone trend studies besides solar cycle (World Meteorological Organization, 2003). Because the ozone response shows variable time lags depending on altitude and latitude the QBO is represented here by two separate components, the zonal wind at $10 \mathrm{hPa}$ and at $30 \mathrm{hPa}$, which are displaced in phase by approximately $\pi / 2$. Since any phase lag can be 

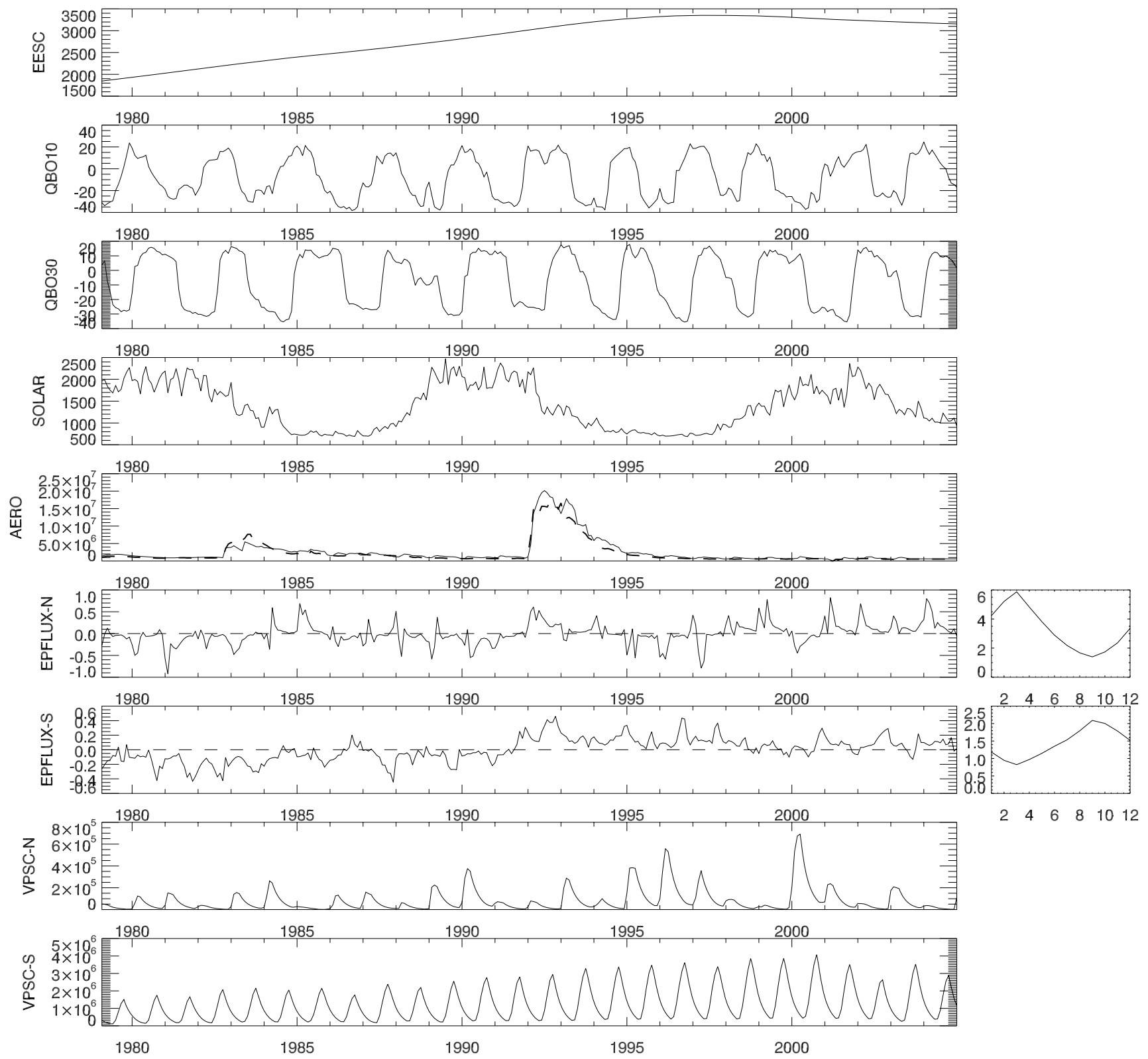

Fig. 2. The time series of monthly proxy data (see also Table 2) from January 1979 to December 2004. The dashed line in panel AERO is the northern hemisphere mean, the solid line the southern hemisphere mean. Tick marks indicate January of each year. For the EPFLUX proxy the deseasonalized data are shown. The mean seasonal cycles are additionally displayed in small panels to the right.

represented by a linear combination of a sine $(\sin (\omega t))$ and a cosine $(\sin (\omega t+\pi / 2))$ the model is able to adapt the correct time lag automatically. This method was first proposed by Bojkov et al. (1995) who used a combination of $25 \mathrm{hPa}$ and $50 \mathrm{hPa}$ winds.

The influence of stratospheric aerosols is often represented in statistical models by an updated version of the NASA stratospheric aerosol optical depths data set of Sato et al. (1993). Here we use instead the vertically integrated stratospheric aerosol surface area density compiled in the framework of the SPARC Stratospheric Aerosol Assessment (Thomason and Peter, 2006).

As a proxy for the Brewer-Dobson circulation we use the vertical component of the EP flux crossing the $100 \mathrm{hPa}$ pressure surface. In each hemisphere we use the flux spatially averaged over the latitudes $45^{\circ}$ to $75^{\circ}$ of the respective hemi- 
sphere. EP fluxes were calculated from ERA-40 analyses before September 2002 and from operational ECMWF analyses thereafter (Wohltmann et al., 2006 ${ }^{1}$ ).

Polar ozone loss due to reactions on polar stratospheric clouds is represented by the potential volume of PSCs given by the volume of air below the formation temperature of nitric acid trihydrate poleward of $60^{\circ}$ in the respective hemisphere. Rex et al. (2004) demonstrated that total ozone loss within the polar vortex depends roughly linearly on wintertime accumulated PSC volume. Temperatures were taken from National Centers for Environmental Prediction (NCEP) reanalyses due to some issues in ERA-40 data (Karpetchko et al., 2005). We have multiplied the PSC volume by EESC to account for the modulation of polar ozone loss by longterm changes in stratospheric chlorine.

In order to account for the cumulating effects of EP flux and PSC volume affecting ozone concentrations several months following their current action, the proxies EPFLUX and VPSC were constructed as

$X_{j}(t)=X_{j}(t-1) \cdot \exp (-\Delta t / \tau)+x_{j}(t)$

where $X_{j}(t)$ is the final EPFLUX or VPSC proxy at time $t$, $\Delta t$ is the time step between $t-1$ and $t, \tau$ is a suitable $1 / e$ decay time, and $x_{j}(t)$ is the original (non accumulated) time series of EP flux or PSC volume. Hence, the effects at the same time accumulate and decay with time. In the extratropics the constant $\tau$ was set to 12 months during the buildup phase (October to March in the NH and shifted by six months in the $\mathrm{SH}$ ) and to 3 months during the rest of the year. In the tropics $\left(30^{\circ} \mathrm{S}\right.$ to $\left.30^{\circ} \mathrm{N}\right) \tau$ was set to 3 months throughout the year. Fusco and Salby (1999) showed that the wintertime ozone buildup is highly correlated with wintertime accumulated EP flux. Because autumn levels are very similar every year (Fioletov and Shepherd, 2003), relating absolute ozone values (e.g. in spring) to accumulated EP flux instead of ozone tendencies seems to be justified. Even though our EPFLUX proxy is not exactly the same as wintertime accumulated EP flux used by Fusco and Salby (1999) due to the relaxation term, they are highly correlated (e.g. $r=0.975$ for April values).

Similarly to the EP flux effects, polar ozone loss is highly correlated with wintertime accumulated PSC volume as mentioned before. Thereafter the ozone columns slowly relax towards a photochemical equilibrium which explains why autumn values are much less variable than springtime columns. Randel et al. (2002) and Fioletov and Shepherd (2003) gave different estimates for this relaxation time scale between 1.5 and "several months". A value of 3 months seems to be a suitable compromise. The results are not very sensitive to this choice ( \pm 1 month). A much larger value of 12 months was chosen for winter to reflect the much longer photochemical lifetime of ozone during these months.

The proxies VPSC and EPFLUX are negatively correlated with each other ( $\mathrm{r}=-0.45$ in the NH for March values). The attribution of variations in ozone to either process is therefore a delicate problem. When VPSC is excluded from the regression model some of its effects are absorbed by EPFLUX. A more important problem is the high correlation between VPSC and EESC in the Southern Hemisphere ( $r=0.91$ for October values, see Fig. 2) which is due to the fact that the PSC volume does not vary strongly from year to year over Antarctica and due to the way the proxy is constructed. The correlation would be even higher without the exceptional situation in 2002 when the polar vortex split into two parts. Results for the proxy VPSC are therefore only shown for the NH where the correlation with EESC is much smaller $(\mathrm{r} \approx 0.38)$ and a separation between the two effects is still possible.

Autocorrelation in the residual time series $\epsilon(t)$ is accounted for by applying the method of Cochrane and Orcutt (1949). Autocorrelations for lags of up to 3 months were considered. This choice is based on careful inspection of the partial autocorrelations which in many cases showed significant values for lags of up to 3 months and much lower values for larger lags. AR(1) coefficients are of the order of 0.5 to 0.6 for the total ozone models, and between 0.6 (in lower stratosphere) and 0.2 (in middle stratosphere) for the models applied to the vertical distribution, which can be understood by the larger lifetime (and hence memory) in the lower stratosphere.

\section{Results and discussion}

If not stated differently the results shown in this section are obtained from a model including all proxies listed in Table 1 with EESC (or alternatively $t$ ) describing the anthropogenic influence and covering the period January 1979 to December 2004. In Sect. 3.1 we first discuss the contribution of the proxies to the variability of both total ozone and its vertically resolved stratospheric distribution. Explanatory variables may not only contribute to variability but also to longterm trends. The remaining linear trend in ozone not explained by variables of natural variability (QBO, solar cycle, aerosols and EP flux), which we therefore attribute to the anthropogenic release of ODSs, will be presented in Sect. 3.2. Finally, the recent evolution of ozone since 1996 and its attribution to different factors is analyzed in Sect. 3.3.

\subsection{Ozone variability}

The overall performance of the regression model (Eq. 1) is presented in Fig. 3 in terms of $R^{2}$ values. Panel (a) shows the $R^{2}$ distribution for the model fits to total ozone. The color contours indicate what fraction of the interannual variability in total ozone seen in a given month and at a given equivalent latitude can be explained by the model. The values are mostly between 0.5 and 0.9 (white to orange). Note that when considering the whole time series instead of only individual months the $R^{2}$ values would be much higher, between about 0.86 over the tropics and Antarctica and 0.97 in 

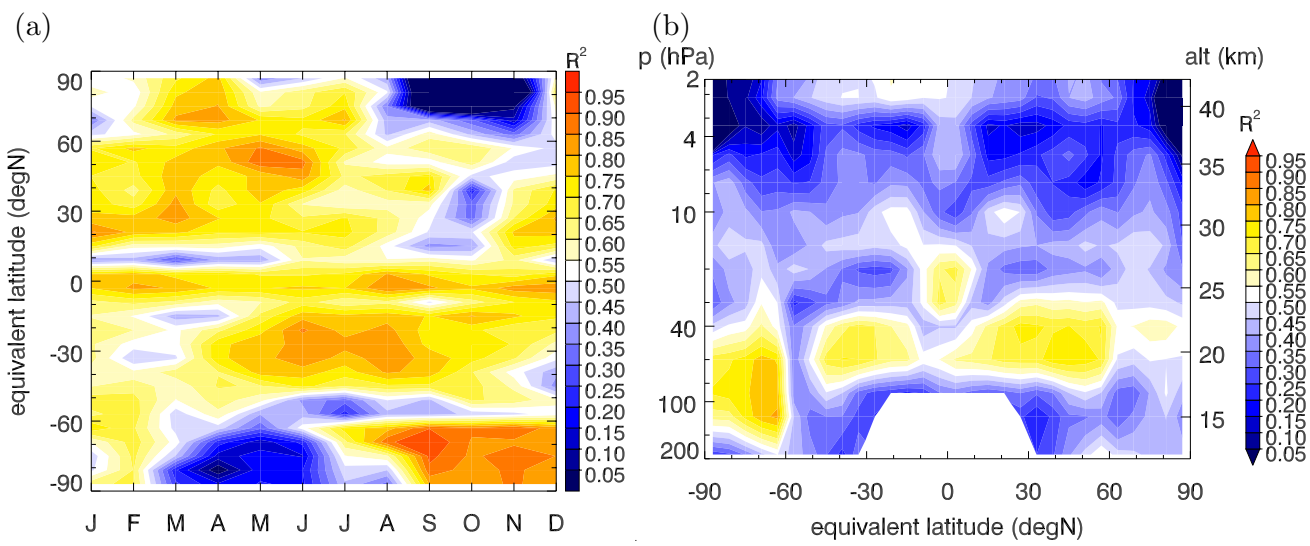

Fig. 3. Quality of regression model fits in terms of explained variance $R^{2}$. (a) Regression to the time series of monthly mean total ozone as a function of equivalent latitude and month. (b) Regression to the monthly mean ozone volume mixing ratios as a function of equivalent latitude and pressure. See text for further details.

northern and southern mid-latitudes, because the variability is usually dominated by the seasonal cycle which can be well reproduced by a model following Eq. (1). A narrow band of high $R^{2}$ values at the equator is flanked by low values at about $10^{\circ}$ on either side of the equator, which is a clear feature of the QBO (see next section). In the subtropics and mid-latitudes, the values are generally high except during autumm in the respective hemisphere. During these months, the interannual variability is generally very low and may be dominated by noise. Poleward of $60^{\circ}$ the low $R^{2}$ values extend from autumn into winter when only little or no light reaches the polar regions. During this time period polar vortex air can only be observed by TOMS when it is pushed equatorward by dynamic perturbations. As the Antarctic vortex is much less perturbed there is only little TOMS data available for assimilation into CATO. Nevertheless, CATO appears to see an increasing proportion of the vortex starting at the edge in June and propagating to the pole by September. From September to December a very high fraction of the interannual variability can be reproduced by the regression model. Interestingly, the model shows a poor performance on the equatorward side of the vortex between $54^{\circ}$ and $60^{\circ} \mathrm{S}$. Possibly this is due to the very large ozone gradients between air inside and outside of the vortex. CATO separates these airmasses based on their equivalent latitude which in turn is based on potential vorticity fields which are clearly not perfect. Figure $3 b$ shows the fraction of interannual variability explained as a function of equivalent latitude and pressure averaged over all months. Note again, that $R^{2}$ values would be mostly above 0.9 when seasonal variability were included. Below $10 \mathrm{hPa} R^{2}$ values are mostly in the range 0.35 to 0.7 with largest values where the variability is dominated by the QBO (see next section) or by polar vortex processes. Above $10 \mathrm{hPa}$ the model performance is mostly poor as expected due to the limitations in the CATO reconstruction method at these altitudes.
The influence of the individual proxies on the variability of total ozone is shown in Fig. 4 as a function of season and equivalent latitude. The contribution of an individual explanatory variable $X_{j}(t)$ to the variance in total ozone is given by $\operatorname{VAR}\left[c_{j}(t) X_{j}(t)\right]$ plus twice the covariances with other variables (which are usually small). Since the regression coefficients $c_{j}(t)$ are constant for a given month of the year (see Eq. 3) the variances can also be expressed as $c_{j}(t)^{2} \cdot \operatorname{VAR}\left[X_{j}(t)\right]$ and standard deviations as $\left|c_{j}(t)\right| \cdot \sigma\left[X_{j}(t)\right]$. In the figure we show values of the signed quantity $c_{j}(t) \cdot \sigma\left[X_{j}(t)\right]$ which may be interpreted as the percentage change in total ozone resulting from a $1 \sigma$ increase in the proxy $X_{j}(t)$. The $1 \sigma$ values of all proxies are given in Table 2 together with their normalized minimum and maximum values.

\subsubsection{Quasi-biennial oscillation}

The QBO signal makes a significant contribution both in a narrow band in the tropics (throughout the year) and in the extratropics poleward of about $15^{\circ}$. A prominent yet mostly insignificant signal is also seen over the North Pole in winter/spring as already noted by Oltmans and London (1982). In the SH roughly the same features are seen as in the $\mathrm{NH}$ but displaced by 6 months. Largest amplitudes in the extratropical ozone QBO are observed during winter/spring in the respective hemisphere in agreement with previous findings (e.g. Yang and Tung, 1994; Randel and Wu, 1996) but the signals are significant through most of the year if both components of the QBO at $30 \mathrm{hPa}$ and $10 \mathrm{hPa}$ are considered. The QBO couples to the seasonal cycle in a complex manner as described by Randel and Wu (1996). In a narrow tropical band between $10^{\circ} \mathrm{N}$ and $10^{\circ} \mathrm{S}$ total ozone is highest when tropical winds are westerly at $30 \mathrm{hPa}$ (April to July) or somewhere between $10 \mathrm{hPa}$ and $30 \mathrm{hPa}$ (during the rest of the year) in agreement for instance with the study of Yang 
(a) $\mathrm{QBO}$ at $30 \mathrm{hPa}$

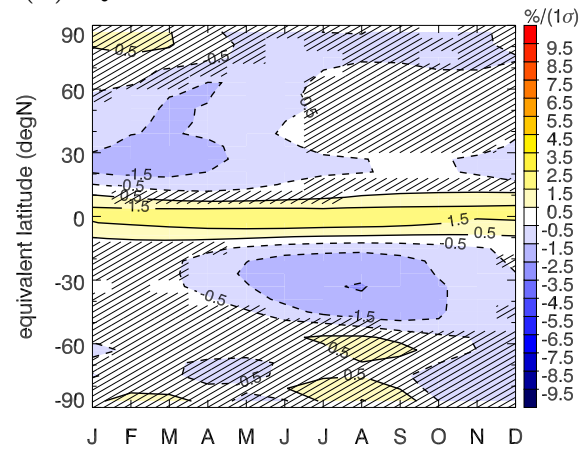

(d) Solar cycle

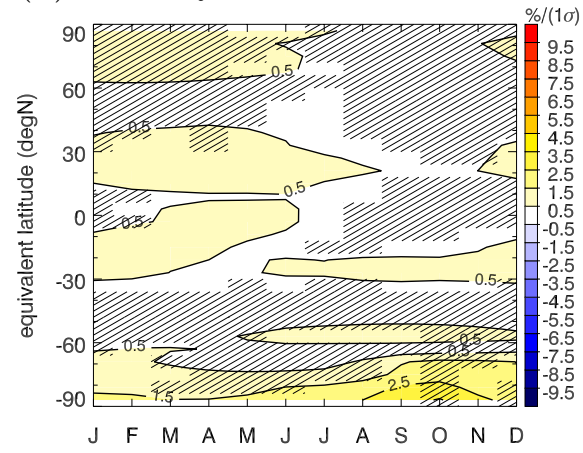

(b) $\mathrm{QBO}$ at $10 \mathrm{hPa}$

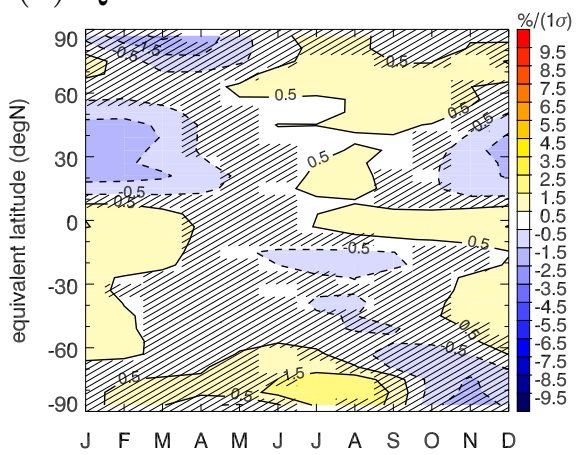

(e) EP flux

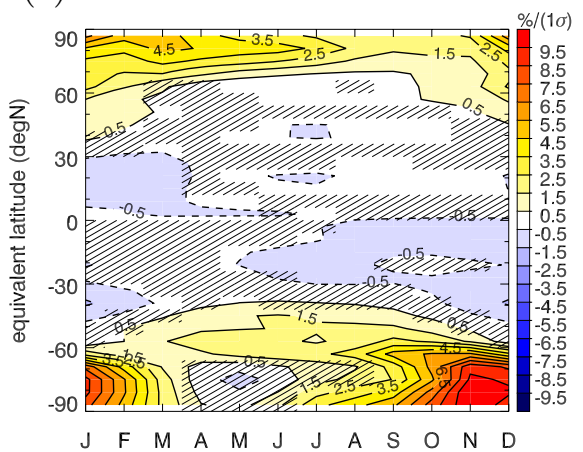

(c) Aerosols

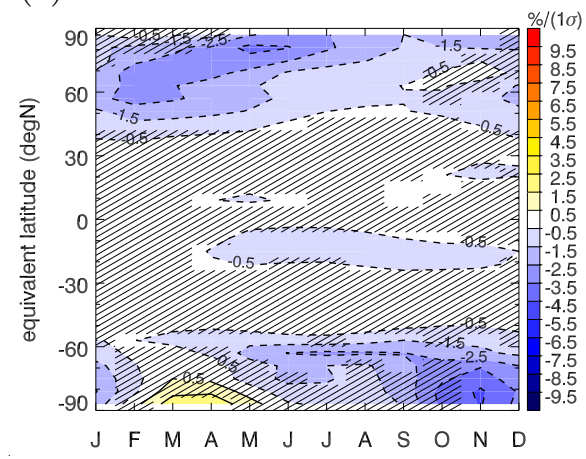

(f) VPSC

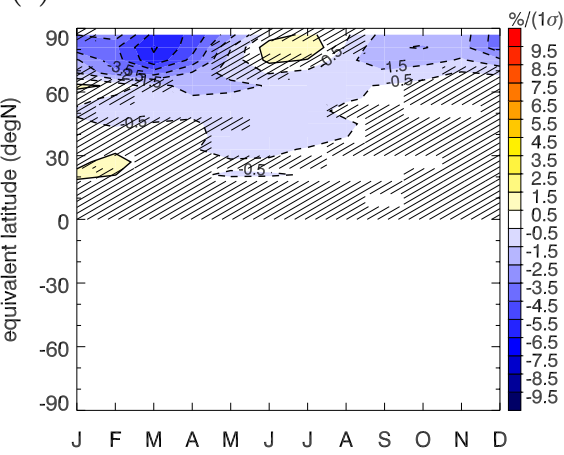

Fig. 4. Contributions to variability in total ozone as a function of season and equivalent latitude. To show all figures in comparable units the regression coefficients were first multiplied by one standard deviation of each proxy time series and then divided by the 1979-2004 mean ozone distribution. Values thus represent the percent change in total ozone for a $1 \sigma$ increase in the corresponding proxy. Shading indicates that the values are statistically not significant at the $95 \%$ significance level. Contour line spacing is $1 \%$.

and Tung (1995). In mid-latitudes, however, the phase lag between total ozone and the QBO is not constant as often assumed in other studies but changes continuously throughout the season. Between July and September, for instance, total ozone anomalies at northern mid-latitudes are in phase with the QBO at $10 \mathrm{hPa}$ but are in opposite phase between December and March.

The annually averaged contributions of the proxies to the variability of stratospheric ozone as a function of equivalent latitude and pressure are presented in Fig. 5. Annual mean coefficients were obtained using a simplified version of the regression model (1) with only one single coefficient estimated per proxy neglecting any seasonal variations (except for the seasonal offset $a$ ). Again, the contributions are shown in terms of percentage change in ozone for a $1 \sigma$ increase in the proxy. Note that all signals are damped above about 30$35 \mathrm{~km}$ altitude due to the relaxation of CATO to a climatology at these levels (see Sect. 2.1).

The vertical structure of the signals provides additional insight into the total ozone responses. The QBO, for instance, has a profound influence on stratospheric ozone in more or less the whole stratosphere (Fig. 5a and 5b). However, the response can be at the same time positive and negative at different altitudes. Summing these opposing contributions over a broad altitude range results in destructive interference and bands of mininum response seen in Fig. $4 \mathrm{a}$ and $4 \mathrm{~b}$ at about $10^{\circ}$ and $60^{\circ}$. In the tropics positive QBO anomalies are seen in Fig. 5a simultaneously in the lower (20-27 km) and upper stratosphere $(>32 \mathrm{~km})$, and a negative one at $28-32 \mathrm{~km}$. This specific two-cell structure has been explained by Chipperfield et al. (1994) based on model studies by the modulation of the mean vertical transport of $\mathrm{O}_{3}$ (lower stratosphere) and $\mathrm{NO}_{\mathrm{y}}$ (upper stratosphere). Reduced $\mathrm{NO}_{\mathrm{y}}$ above $30 \mathrm{~km}$ results in less $\mathrm{NO}_{\mathrm{x}}$-catalyzed ozone loss and hence higher $\mathrm{O}_{3}$.

The two fields in Fig. 5a and 5b are similar to the two anomaly patterns SVD1 and SVD2 in Fig. 6 of Randel and Wu (1996) which were obtained by singular value decomposition (SVD) thus representing the two dominating modes of ozone variability associated with the QBO. The similarity with our patterns suggests that the SVD1 and SVD2 modes basically represent the ozone signatures of the QBO about one quarter cycle $(\pi / 2)$ out of phase. Using CATO, we are able to extend the patterns beyond the previous limits of $60^{\circ} \mathrm{S}-60^{\circ} \mathrm{N}$. We observe distinct signals of the QBO over the poles between about $25 \mathrm{~km}$ and $30 \mathrm{~km}$ supporting findings of Oltmans and London (1982) and Garcia and Solomon (1987). 
(a) $\mathrm{QBO}$ at $30 \mathrm{hPa}$

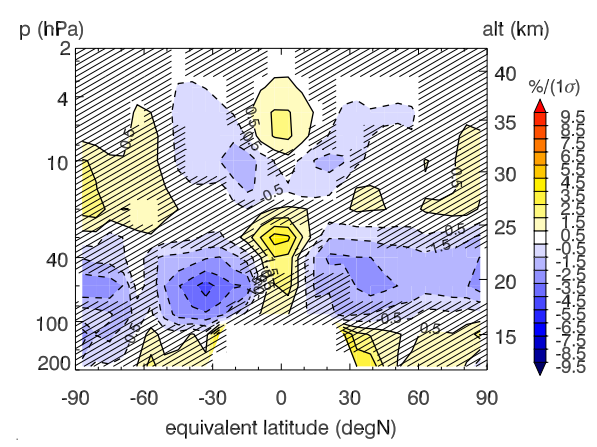

(d) Solar cycle

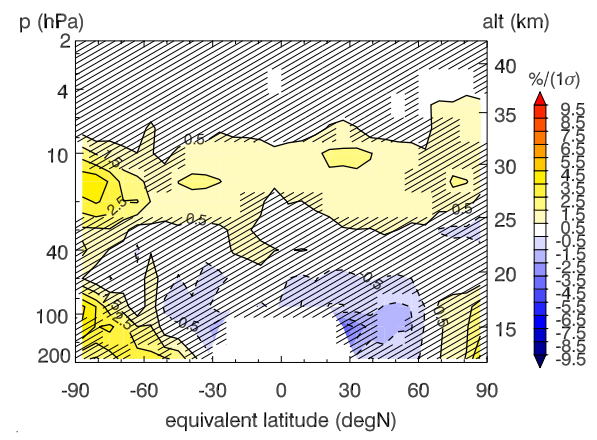

(b) $\mathrm{QBO}$ at $10 \mathrm{hPa}$

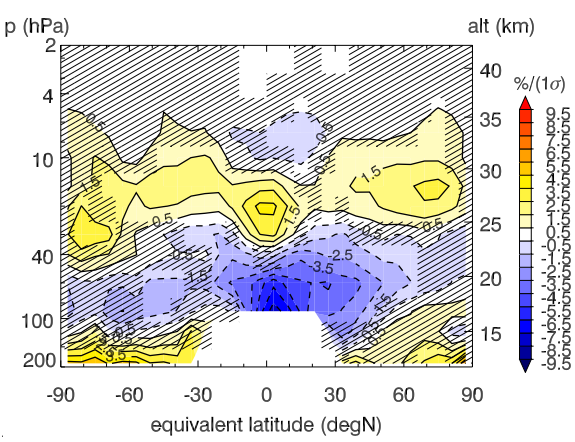

(e) EP flux

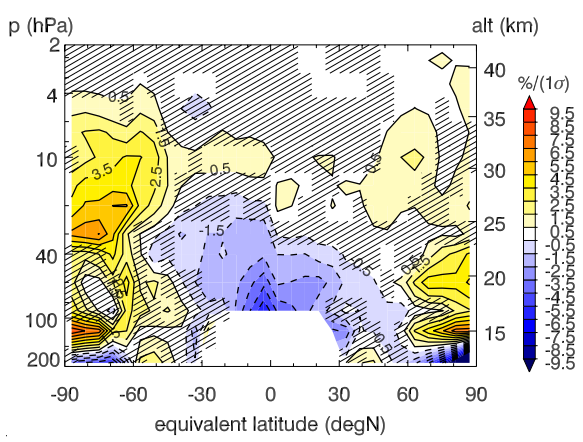

(c) Aerosols

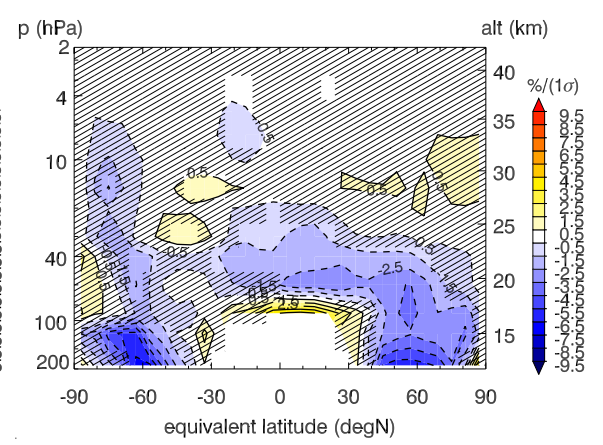

(f) VPSC

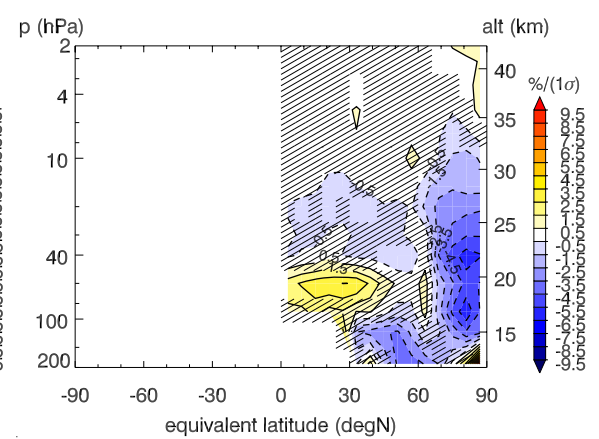

Fig. 5. Annual average contributions to variability in ozone partial pressure as a function of equivalent latitude and pressure. Values are given as percent change in ozone for a $1 \sigma$ change in the corresponding proxy. See Fig. 4 for further details.

\subsubsection{Volcanic eruptions}

The increased aerosol surface area density following volcanic eruptions affects stratospheric ozone both through changes in heterogeneous chemistry (Solomon et al., 1996) and through changes in dynamics due to the radiative impact of the aerosol (Kodera, 1994). The ozone perturbations shown in this section mainly represent the signal from the eruption of Mount Pinatubo $\left(15^{\circ} \mathrm{N}\right)$ in June 1991. The eruption of El Chichón in 1982 had a much lower impact on aerosol surface area densities (see Fig. 2). Studying its effects would therefore require a separate analysis which is beyond the scope of this paper. In CATO the effect on total ozone values is most evident at mid to high northern latitudes during the winter and spring months (Fig. 4c). Pinatubo appears to have more strongly perturbed the stratospheric trace gas composition in the $\mathrm{NH}$ than in the $\mathrm{SH}$ despite the fact that the volcanic aerosol had spread out more or less equally into both hemispheres (Trepte et al., 1993; Jackman et al., 1996). The distribution and timing of the volcanic signal in 4c agrees well with other observations (e.g. Randel and $\mathrm{Wu}, 1995)$. One exception is that the low latitude signature was previously reported to be centered over the equator whereas we find maximum impacts at about $15^{\circ}$ on either side of the equator though clearly more pronounced in the
SH (see Fig. 4c). The range of aerosol surface area densities between background levels and the period following Pinatubo is about five standard deviations (see Tab. 2). From this we deduce maximum ozone depletions of about 2-4\% (5-10 DU) at low latitudes, $11-14 \%$ (50-60 DU) at northern high latitudes $\left(>50^{\circ} \mathrm{N}\right)$, and $15-18 \%(40-50 \mathrm{DU})$ at southern high latitudes. These numbers agree closely with results from observations (Herman and Larko, 1994; Randel and $\mathrm{Wu}, 1995$ ) or from numerical simulations (Rosenfield et al., 1997; Jackman et al., 1996) but are higher than in the model study of Kinnison et al. (1994).

In mid-latitudes, the signal is much more significant in the northern hemisphere. It peaks around February and becomes insignificant in August/September. The studies of Hadjinicolaou et al. $(1997,2002)$, which are based on 3-D chemistrytransport simulations with parameterized chemistry, suggest that this signal can largely be explained by changes in dynamics following the eruption of Mount Pinatubo. However, the dynamical mechanism remains unclear and 2-D model studies suggest that the radiative impact of the aerosols should rather lead to a slight increase in mid-latitude ozone (Rosenfield et al., 1997).

Over both poles the springtime ozone depletion is enhanced in the presence of volcanic aerosols. The depletion starts in mid-winter at about $60^{\circ} \mathrm{N}$ and $60^{\circ} \mathrm{S}$ and then prop- 
agates poleward. Over Antarctica the depletion reaches its maximum not before November and hence appears to be significantly delayed relative to the ozone depletion on PSCs expected to peak in October. These results are in good correspondence with the model study of Rosenfield et al. (1997) who explained the delay over the south pole by the effects of the aerosol on photolysis rates leading to more $\mathrm{Cl}_{\mathrm{y}}$ being stored as $\mathrm{HOCl}$ rather than $\mathrm{Cl}_{2}$ during polar night. $\mathrm{HOCl}$ is less readily photolyzed than $\mathrm{Cl}_{2}$ leading to a delayed buildup of $\mathrm{ClO}_{\mathrm{x}}$.

The vertical distribution of the annual mean ozone response to volcanic eruptions shows negative values throughout the lower stratosphere maximizing at about $60^{\circ}$ where it extends down to the tropopause level in both hemispheres (Fig. 5c). In the SH extratropics the signal mainly occurs below $100 \mathrm{hPa}$ which may explain why it has been missed in previous analyses of satellite data. In the tropics a significantly negative response is found above the tropical tropopause up to about $28 \mathrm{~km}$. In northern mid- to high latitudes there is a change from negative to positive influences at $25 \mathrm{~km}$ altitude. This agrees very well with ozone anomalies measured from sondes at Boulder, USA $\left(40^{\circ} \mathrm{N}\right)$ (Hofmann et al., 1994), which show a change to positive values at $24 \mathrm{~km}$. The model studies of Rosenfield et al. (1997), Solomon et al. (1996) and Zhao et al. (1997) suggest that in the extratropics the main reason for this change in sign is heterogeneous chemistry on the increased aerosol surface. Heterogeneous reactions reduce the concentration of $\mathrm{NO}_{\mathrm{x}}$ but increase $\mathrm{ClO}_{\mathrm{x}}$ and $\mathrm{HO}_{\mathrm{x}}$. Reduced $\mathrm{NO}_{\mathrm{x}}$ leads to more ozone above $25 \mathrm{~km}$ whereas below that level the increases in $\mathrm{ClO}_{\mathrm{x}}$ and $\mathrm{HO}_{\mathrm{x}}$ outweigh the reductions in $\mathrm{NO}_{\mathrm{x}}$ leading to enhanced ozone depletion. The good agreement of CATO with these studies supports the notion of Solomon et al. (1996) that heterogeneous chemistry played an important role in shaping the ozone response in northern mid-latitudes in addition to the dynamical effects proposed by Hadjinicolaou et al. (1997).

\subsubsection{1-year solar cycle}

The effect of the 11-year solar cycle on total ozone is shown in Fig. 4d. An accurate account for solar variability is essential since it may significantly affect ozone trend estimates (World Meteorological Organization, 2003; Steinbrecht et al., 2004). However, there is presently little consensus on the exact structure of the solar cycle signal and such estimates generally suffer from the short data records and from the temporal alignment of the solar cycles with the eruptions of El Chichón and Pinatubo (Solomon et al., 1996; McCormack et al., 1997; Lee and Smith, 2003). Including the latest cycle (cycle 23) should allow us to better separate between the different effects as it was not synchronized with a major volcanic eruption (see Fig. 2). A further complication is that solar cycle effects at high latitudes are modulated by the QBO (Labitzke and van Loon, 2000) or rather, that the QBO itself is modulated by the solar cycle (Salby and Callaghan, 2000). More recent model and observation-based studies support the initial findings of (Salby and Callaghan, 2000) that solar variability induces a decadal-scale modulation of the QBO period (McCormack, 2003; Salby and Callaghan, 2006). An example for the connection between QBO and solar effects is the observation that solar cycle variations in total ozone are significantly larger during easterly phases of the QBO than during westerly phases (Steinbrecht et al., 2003). A second problem affecting the separation between QBO and solar effects is caused by the interaction between the annual cycle and the QBO which can induce a decadal scale oscillation (Salby et al., 1997). This oscillation happened to be $180^{\circ}$ out of phase with the solar flux variation during cycles 21 and 22. Solar variability regression analyzes based on this time period therefore seem to be strongly affected by interferences with QBO as demonstrated by Lee and Smith (2003). As for the aerosols, the latest solar cycle was not synchronized with the QBO in the same way the previous cycles allowing for a somewhat better separation of the different effects. This may explain differences between our results and earlier studies to some degree.

As shown in Fig. 4d total ozone is generally elevated during periods of maximum solar activity (e.g. Brasseur, 1993; Hood, 1997; Steinbrecht et al., 2003). The low latitude signal appears to be strongest between January and July but seasonal differences are generally small. Similar to the above studies we find that the amplitude of the signal has a local minimum near the equator. The 2-D model study of Brasseur (1993) reported a steady increase in the signal from the equator towards the poles which contrasts with the pattern derived from CATO. Significant regression coefficients are in fact only found between $10^{\circ}$ and $35^{\circ}$ in the $\mathrm{NH}$ and somewhat closer to the equator in the SH. The signal is mostly insignificant in mid-latitudes and is again larger over the poles during the respective spring season, in agreement with the study of Brasseur (1993). The modification of polar stratospheric temperatures and geopotential height by the 11-year solar cycle during the northern winter is well documented (Labitzke, 1987; van Loon and Labitzke, 1994) whereas the influence on the high latitude ozone distribution is much less well known due to a lack of observations. Our results indicate that total ozone over Antarctica is sensitive to solar cycle variability in particular during late spring. Since the range of $\mathrm{Mg}$ II index values is about 3.5 standard deviations (Table 2), total ozone is up to $10 \%$ higher over Antarctica during solar maximum than during solar minimum which contrast strongly with the value of less than $2 \%$ derived by Brasseur (1993). At low latitudes we find the changes to be below $3 \%$.

The vertical pattern is shown in Fig. 5d. For comparison, Fig. 6 shows the same graph for the combined CATO/SBUV data set (see Sect. 2.1). This version produces a more realistic picture at altitudes above $30 \mathrm{~km}$ where the signal is damped in Fig. 5d due to the relaxation towards an ozone climatology. However, the quality of the long-term SBUV record is 
under debate because of intersatellite calibration issues (e.g. Steinbrecht et al., 2006). A second problem may be related to ERA-40 temperatures in the upper stratosphere which are known to exhibit stepwise shifts due to the assimilation of certain satellite data (Uppala et al., 2005). The CATO/SBUV data set is sensitive to errors in the ERA-40 temperatures because the SBUV data were interpolated from pressure levels onto the native potential temperature levels of CATO. Given these limitations and the general problems with disentangling different effects mentioned earlier, the results presented in the following should be interpreted with care.

The main feature is a positive response maximizing at about $10-20 \mathrm{hPa}(27-32 \mathrm{~km})$ with a relatively uniform distribution extending from pole to pole. In the combined CATO/SBUV data set the signal extends up to about $38 \mathrm{~km}$ in mid-latitudes and up to the highest level $(>40 \mathrm{~km})$ over Antarctica. The solar cycle signal is located at lower altitudes than reported in the model studies of Brasseur (1993), Langematz et al. (2005) and Lee and Smith (2003) (about $32-38 \mathrm{~km}$ ) but relatively close to the results of Egorova et al. (2005) $(30-35 \mathrm{~km})$. It is also substantially lower than reported from previous observation studies. Results based on satellite measurements suggested largest relative increases from solar minimum to maximum occurring in mid-latitudes near the stratopause between 40 and $50 \mathrm{~km}$ (McCormack and Hood, 1996; Wang et al., 1996; Lee and Smith, 2003; Zerefos et al., 2005). Unfortunately, this altitude range is not covered in our analysis. These studies further reported on a significant negative anomaly in the tropical stratosphere at 30-35 km (McCormack and Hood, 1996; Wang et al., 1996; Lee and Smith, 2003) or slightly higher (Zerefos et al., 2005) which is completely absent in our analysis. We do not find such a signal even if we exclude the latest solar cycle. Such a negative signal contrasts with model results which tend to show a generally positive response maximizing well below $40 \mathrm{~km}$ with either a monopolar structure centered over the tropics (Lee and Smith, 2003), a relatively uniform signal between $\pm 60^{\circ}$ (Brasseur, 1993; Egorova et al., 2004, 2005), or showing almost no change in the stratosphere (Huang and Brasseur, 1993). A weak negative signal in the tropical lower stratosphere could only be reproduced by Langematz et al. (2005) which was the first study to include an idealized source of $\mathrm{NO}_{\mathrm{x}}$ from high-energy electrons maximizing during solar minimum. A similar dipole pattern as in the observations could also be reproduced by Lee and Smith (2003). However, they demonstrated that this is not due to solar cycle variation but rather to the interference with QBO and volcanic eruptions in the statistical analysis.

As in total ozone the largest effects are seen over Antarctica with annually averaged ozone being enhanced by about $7 \%$ during solar maximum relative to solar minimum above $30 \mathrm{hPa}$ as well as below $80 \mathrm{hPa}$. Over the Arctic the signal is generally much weaker and it is only mildly significant at the upper levels. These observations provide some support for the 3-D numerical simulations of Langematz et al. (2005)

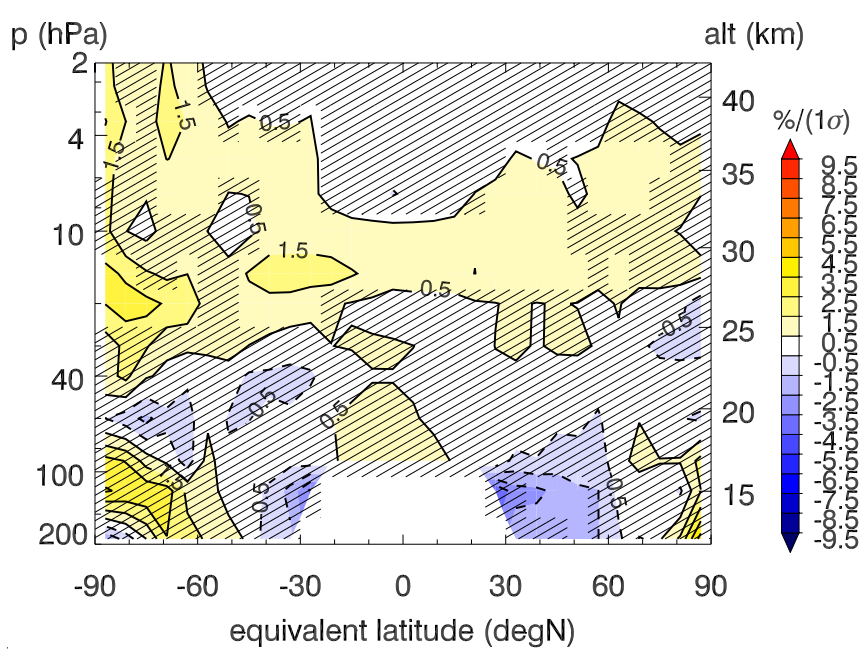

Fig. 6. 11-year solar cycle signal in CATO version with SBUV Version 8 data assimilated in upper stratosphere.

who found the largest ozone changes at polar latitudes.

\subsubsection{Brewer-Dobson circulation}

The Brewer-Dobson circulation has a profound impact on total ozone concentrations at high northern latitudes between December and June (Fig. 4e). It explains a dominant fraction of the generally large variability over this region. Between December and February the influence extends down to $40^{\circ} \mathrm{N}$. Note that the ozone signal shown refers to one standard deviation of the EPFLUX proxy values of the respective month. January values, for instance, refer to one standard deviation of all January EPFLUX values. It is thus a measure of interannual variability rather than of the seasonal amplitude of variation which would be much larger. An intensified circulation is associated with a weak polar vortex and correspondingly high total ozone values over the poles and reduced values at low latitudes (Fusco and Salby, 1999). Between $30^{\circ}$ and $50^{\circ} \mathrm{N}$ the effect of EP flux variations is minimal. The pattern is similar in the SH but shifted by six months. EP flux is strongest between October and February in the $\mathrm{NH}$ and drops to very low values between May and July. The integrated amount of EP flux entering the stratosphere over the winter determines the buildup of ozone from autumn until spring. Thereafter ozone concentrations relax towards photochemical equilibrium on a timescale of a few months (Randel et al., 2002; Fioletov and Shepherd, 2003). Total ozone therefore remains correlated to the spring time values and hence to wintertime accumulated EP flux throughout the summer (Fioletov and Shepherd, 2003). This is also seen in Fig. 4e where total ozone anomalies remain significantly influenced by EP flux until the following autumn. 

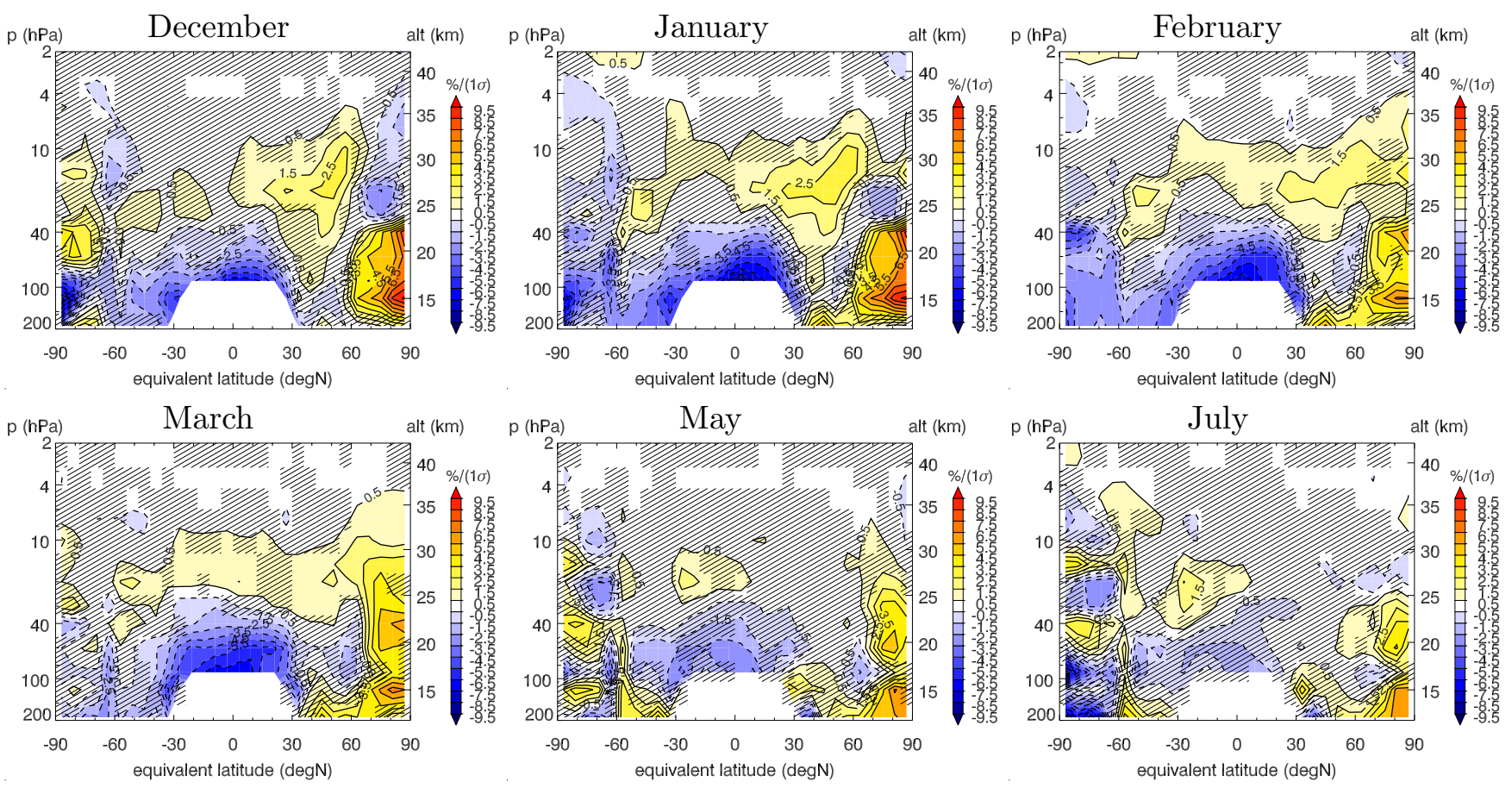

Fig. 7. Sequence of the influence of northern hemisphere EP flux variations on the global stratospheric ozone distribution in selected months. Values are given as percentage change in ozone for a $1 \sigma$ change in the EPFLUX proxy in the given month.

In the SH the situation is somewhat more complicated. The EP flux is generally weaker due to lower wave activity and has a less pronounced annual cycle. Similar to the NH a positive anomaly appears in mid-latitudes in autumn and lasts until the following spring or actually somewhat longer in the SH. Yet, there is a distinct difference between the two hemispheres at polar latitudes. The signal appears much later in the $\mathrm{SH}$ and also the peak influence is delayed by roughly two months. The absence of a strong signal between April and September is likely a consequence of the Antarctic vortex being much more isolated than the Arctic one as already noted by Dobson (1968). The Antarctic vortex is therefore less disturbed by wave activity (and hence variations in EP flux) which may for instance lead to sudden stratospheric warmings in the $\mathrm{NH}$ but not in the $\mathrm{SH}$.

The vertical distribution of the annual mean influence of EP flux variations is shown in Fig. 5e. Elevated ozone is mainly found poleward of $60^{\circ}$ in the lower stratosphere and down to about $40^{\circ}$ above $25 \mathrm{~km}$ in both hemispheres. In the SH the positive anomaly in the lower stratosphere extends to lower latitudes which explains the more prominent anomaly seen in the total columns (Fig. 4e). The enhanced transport to high latitudes is associated with a decrease in ozone in the tropical lower stratosphere. This is clearly visible up to about $25 \mathrm{~km}$ in the $\mathrm{NH}$ and somewhat higher up in the $\mathrm{SH}$. Note that in each hemisphere we only accounted for the EP flux of the respective hemisphere. The influence of the $\mathrm{NH}$ extratropical pump on the SH and vice versa is excluded in this view.

Figure 7 therefore shows a sequence of the influence of NH EP flux only on the global ozone distribution for selected months. As expected, the influence builds up in the $\mathrm{NH}$ from December to March/April and weakens thereafter. The largest buildup occurs north of $60^{\circ} \mathrm{N}$ below $23 \mathrm{~km}$. Above $25 \mathrm{~km}$ a positive anomaly is located at about $50^{\circ} \mathrm{N}$ in December which appears to slowly progress northwards until March. The region of reduced ozone in the tropical lower stratosphere $(<24 \mathrm{~km})$ extends well into the $\mathrm{SH}$ as reported also by Fusco and Salby (1999) based on MLS measurements. Negative ozone responses are not only seen near the equator but at least up to $50^{\circ} \mathrm{S}$ in the lower stratosphere.

At higher levels above $22-25 \mathrm{~km}$ the response to increased EP flux is positive in both hemispheres. The positive signal in the SH is strongest between January and March and appears to have a local maximum around $50^{\circ} \mathrm{S}$. This anomaly may be related to the strongly enhanced upward transport in the $\mathrm{SH}$ upper stratosphere (maximum at about $20^{\circ} \mathrm{S}$ ) reported by (Solomon et al., 1986) which produces a strong increase in $\mathrm{CH}_{4}$ and $\mathrm{N}_{2} \mathrm{O}$ from November to February as observed from satellites. Using a prognostic model, Solomon et al. (1986) demonstrated that this transport is not induced locally but rather by forcing from the northern hemisphere. Similarly, Salby and Callaghan (2004) analyzed tendencies (e.g. from November to March) of ozone and meteorological pa- 
rameters and found that amplified wave forcing in the winter hemisphere leads to anomalous upwelling in the summer hemisphere, with largest changes over the polar cap. According to their analysis, the ozone response in the summertime polar stratosphere is thus in phase with the response in the tropics. This seems to be confirmed by Fig. 7 where January and February anomalies are significantly negative in the Antarctic lower stratosphere, in phase with the negative tropical anomalies. In the $\mathrm{NH}$, the polar anomaly significantly weakens between March and July which is a result of rapid mixing throughout the extratropics once the polar vortex breaks down (Fioletov and Shepherd, 2005). As a result the ozone anomalies remain positive in the lower stratosphere $(>100 \mathrm{hPa})$ in mid-latitudes between May and July. Above $20 \mathrm{~km}$ altitude a positive anomaly remains until at least July which is in good agreement with results from a Lagrangian model study by Konopka et al. (2003) which demonstrates that vortex remnants at this level are "frozen in" in the summer circulation without much mixing.

\subsubsection{Ozone depletion on PSCs}

For reasons described in Sect. 2.2 results for the variable VPSC are only shown for the NH. As expected, the influence on total ozone is strongest between February and April north of $70^{\circ} \mathrm{N}$ (Fig. 4f). Interestingly, the anomaly spreads to low latitudes, i.e. down to at least $30^{\circ} \mathrm{N}$, between April and July suggesting a significant impact of polar ozone depletion on mid-latitude ozone during summer. Notably this effect can not be reproduced by EPFLUX even if VPSC is excluded from the regression model. Given the fact that the range between minimum and maximum PSC volume is about 4 standard deviations (see Tab. 2) we may estimate that midlatitude ozone is up to $4 \%$ lower in a summer following a cold Arctic winter than following a warm winter due to the effect of polar ozone depletion alone. Using a 3-D chemistrytransport-model, Chipperfield (1999) calculated reductions of $2-3 \%$ at $50^{\circ} \mathrm{N}$ due to the effects of chlorine activation on cold liquid aerosols, nitric acid trihydrate and ice particles. Compared to our results these values are too low in particular given the fact that they do not only include polar but also mid-latitude heterogeneous ozone losses. Similar problems have been reported for other numerical simulations (World Meteorological Organization, 2003) but recent model updates have strongly improved the agreement with observed Arctic ozone depletion (Chipperfield et al., 2005). Knudsen and Groß (2000) used reverse domain filling trajectories to calculate the dilution of mid-latitude air by ozone depleted air from the vortex. They found reductions in $30^{\circ}-60^{\circ} \mathrm{N}$ mean total ozone due to dilution of the order of 3\% in spring 1995 and 1997, respectively, following two exceptionally cold Arctic winters. The dilution effect extends down to about $30^{\circ} \mathrm{N}$ within the first two months after breakup of the vortex. These results agree well with our estimate of a maximum effect of $4 \%$ and the seasonal evolution shown in Fig. 4f.

Unlike the pattern for total ozone the vertical distribution is quite noisy as seen in Fig. 5f. The problems of the regression analysis to distinguish between effects of VPSC and effects of EPFLUX is quite obvious when comparing panels e and $\mathrm{f}$. At high northern latitudes at $17 \mathrm{~km}$ for instance, the EP flux signal shows a pronounced minimum. This minimum is compensated by VPSC which shows a distinct negative maximum at the same place. VPSC contributions are largest north of about $65^{\circ} \mathrm{N}$ as expected, but contributions are also seen in the lower stratosphere $(13-17 \mathrm{~km})$ in mid-latitudes. As suggested by Fig. 4f, the latter is probably due to southward transport of polar air depleted in ozone between April and July following the break-up of the polar vortex. The low latitude signals south of $40^{\circ} \mathrm{N}$ are probably due to the imperfect separation between EP flux and VPSC effects. In a simulation excluding VPSC the EP flux anomalies tend to become more pronounced at these points.

\subsection{Ozone trends}

Figure 8 compares residual linear trends (coefficient $b$ in Eq. 1 and 2) in total ozone estimated for the period 1979 to 1995 (upper panels) and for 1979 to 2004 (lower panels). The term "residual" in this context means that the influence of natural variability, i.e. of volcanic aerosols, solar cycle, EP flux and QBO, on the trend is removed. Results are only shown for the model excluding VPSC because this proxy also contains an anthropogenic component (due to multiplication by EESC) and because of its collinearity with EESC in the $\mathrm{SH}$. The figures can thus be interpreted as representing the overall trend due to man-made increases in EESC which influences both polar processes as well as ozone depletion at non-polar latitudes. It should be cautioned that over Antarctica a linear model is of limited value because after 1987 ozone depletion continued at a smaller rate than before relative to the increase in EESC due to saturation of the ozone depletion in the vortex interior (Jiang et al., 1996).

The two left-hand panels are linear trends (in \%/decade relative to the period mean ozone) whereas the right-hand panels show the influence of EESC (in DU/ppt) directly. Because EESC increased almost linearly between 1979 and 1995 (see Fig. 2) panels (a) and (b) look very similar. For the period 1979 to 2004, however, the two panels (c) and (d) are distinctly different. The linear trend is significantly smaller than for 1979 to 1995 , in particular for mid- to high latitudes in winter and spring in the respective hemisphere. This suggests that even after removing the influences of natural variability the ozone trend was substantially lower (i.e. less negative or even positive) after 1995 than before. The proxy EESC represents the anthropogenic influence more directly. Because EESC reached a maximum in 1997 and started decreasing thereafter it seems to better represent the evolution of ozone than a simple linear trend. The EESC coefficients are in fact similar for both periods (compare panels $b$ and d) 
(a) Linear trend 1979-1995

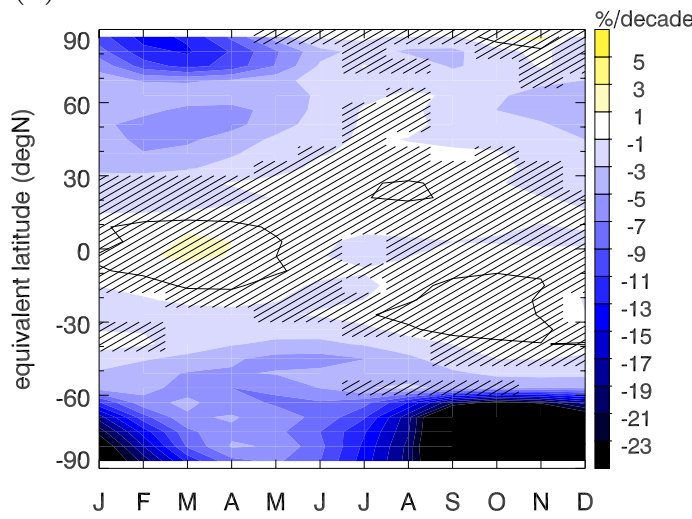

(c) Linear trend 1979-2004

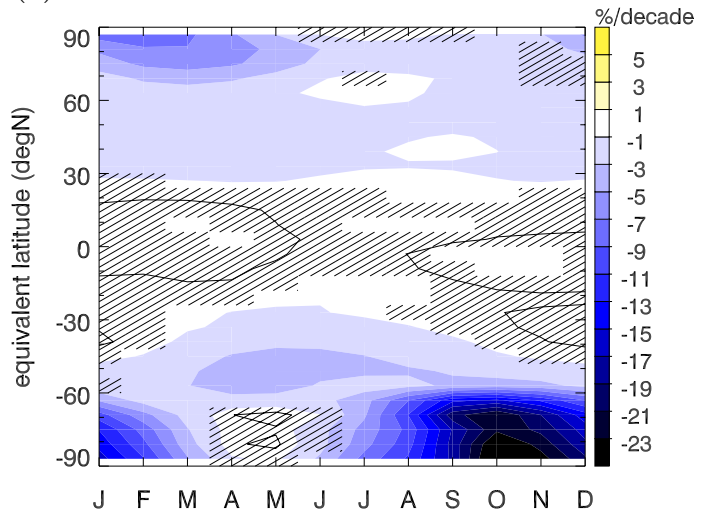

(b) EESC coefficient 1979-1995

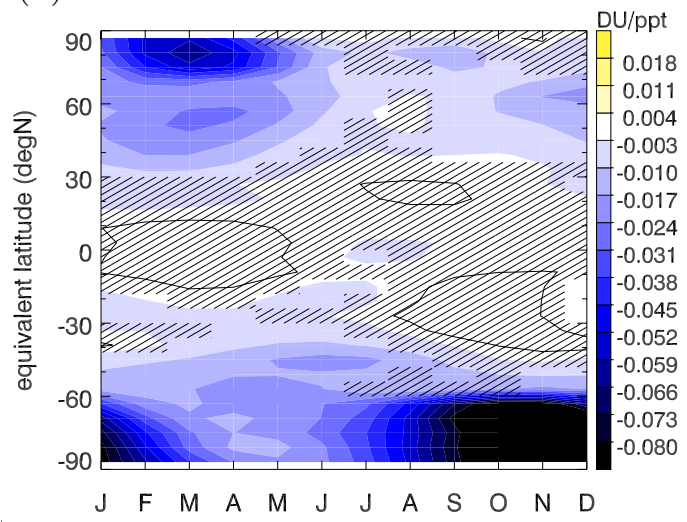

(d) EESC coefficient 1979-2004

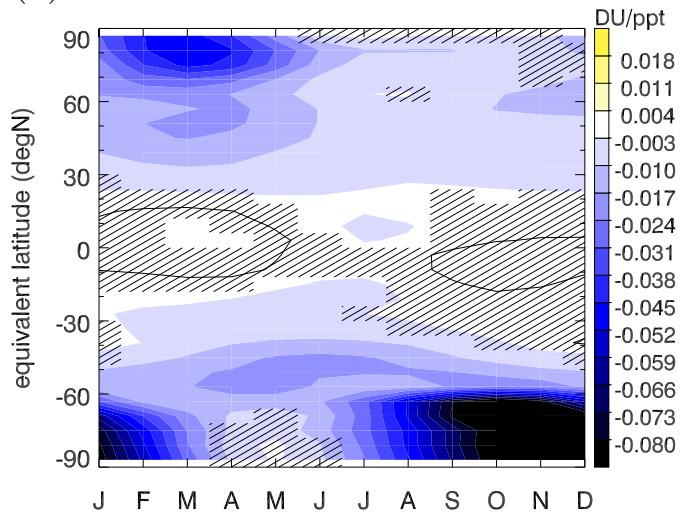

Fig. 8. Model estimates of the anthropogenic influence on ozone trends. Panels (a) and (c) show the linear trend component (coefficient $b$ ) in percent per decade for two different time periods, 1979-1995 and 1979-2004, respectively, for the full model but excluding the influence of VPSC. Panels (b) and (d) show the influence of changes in EESC on total ozone (DU/ppt) calculated with the same model but with EESC instead of a simple linear trend.

(a) Linear trend 1979-2004

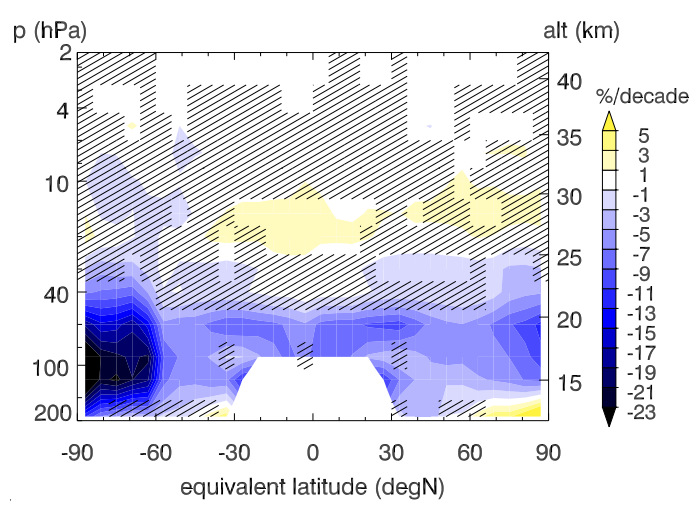

(b) EESC coefficient 1979-2004

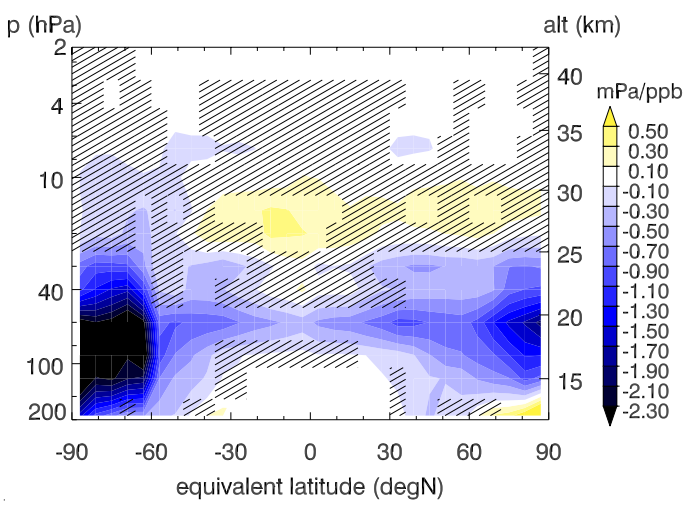

Fig. 9. Model estimates of the anthropogenic influence on ozone profile trends. (a) Linear trend component (coefficient $b$ ) in percent per decade for the full model but excluding the influence of VPSC. (b) Influence of changes in EESC on ozone partial pressure (mPa/ppb) calculated with the same model as (a) but with EESC instead of a linear trend. 
confirming that ozone and EESC evolved in a similar way after 1995. This point is analyzed in more detail in Sect. 3.3.

In the $\mathrm{NH}$ the largest negative trends are seen in February and March at high equivalent latitudes, i.e. within the polar vortex, with values of up to $-13 \% / d e c a d e$ for 1979 1995 and up to $-9 \% / d e c a d e$ for 1979-2004. Notably there is a second maximum at mid-latitudes around March which seems to be detached from the polar maximum and which occurs too early to be explained by dilution with vortex air. This is likely an indication of mid-latitude ozone depletion which is thought to be controlled by heterogenous chemistry leading to enhanced chlorine activation (Solomon et al., 1996). Since this process is closely related to the reduction of $\mathrm{NO}_{\mathrm{x}}$ by hydrolysis of $\mathrm{N}_{2} \mathrm{O}_{5}$ on aerosols it is conceivable that its effect is strongest during winter when $\mathrm{N}_{2} \mathrm{O}_{5}$ hydrolysis is largest. Trends in mid-latitudes are largest in March and are of the order of $-5 \% /$ decade for 1979-1995 but only $-2 \% / d e c a d e$ for 1979-2004. EESC decreased by $195 \mathrm{ppt}$ from its maximum in 1997 to the end of 2004. Given regression coefficients of about $0.018 \mathrm{DU} / \mathrm{ppt}$ in mid-latitudes and $0.055 \mathrm{DU} / \mathrm{ppt}$ at polar latitudes this corresponds to an ozone increase since 1997 of up to $3.5 \mathrm{DU}$ in mid-latitudes and up to $11 \mathrm{DU}$ over the Arctic, respectively, due to the effects of the Montreal Protocol. A much larger recovery of the order of $20 \mathrm{DU}$ is expected for Antarctic springtime ozone. However, EESC as used here is not representative for the Arctic and Antarctic stratosphere. Because the air is much older in the polar stratosphere the peak in EESC will likely be delayed here by some 2 to 3 years as compared to mid-latitudes (Newman et al., 2006). Hence, a significant increase in ozone owing to the reduction in EESC cannot yet be expected by the end of 2004.

SH mid-latitude trends are similar to those in the $\mathrm{NH}$ with values of $-3 \%$ to $-5 \% /$ decade for $1979-1995$ and about $-2 \%$ to $-3 \% /$ decade for $1979-2004$. Negative trends tend to be largest in April/May which appears to be too late to be explained by dilution with vortex air depleted in ozone. The seasonal variation of the trend is generally much smaller than in the NH. Near the equator long-term trends are close to zero and mostly insignificant.

Figure 9 shows the vertical distribution of the annual mean linear trend (Fig. 9a) and influence of changes in EESC (Fig. 9b). Largest downward trends (1979-2004) of more than $20 \% /$ decade are seen over the Antarctic below $40 \mathrm{hPa}$ (or $23 \mathrm{~km}$ ), sharply separated at $60^{\circ} \mathrm{S}$ from the much lower trends of about $-5 \% /$ decade in mid-latitudes. Significantly negative annual mean downward trends of up to $10 \% /$ decade are also seen over the Arctic. The maximum negative trend is located at about $19 \mathrm{~km}$ altitude but it is less well confined in latitude as over the Antarctic which reflects the nature of the Arctic vortex being more perturbed.

The low and mid-latitude trends are remarkably symmetric in the two hemispheres. Both the linear trend and EESC show a vertically well confined band of significant downward trends near $18-20 \mathrm{~km}$ altitude extending from about $40^{\circ} \mathrm{S}$ to

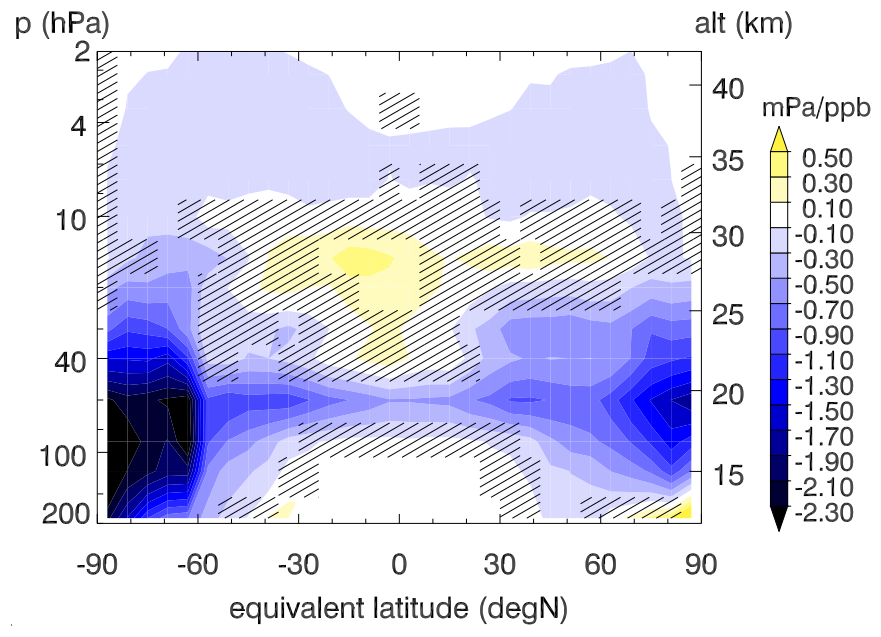

Fig. 10. Same as Fig. 9b but for CATO version with SBUV Version 8 data assimilated in upper stratosphere and only for the period 1979-2003.

$40^{\circ} \mathrm{N}$. It peaks at $30^{\circ}$ north and south of the equator reaching values of about $-8 \% /$ decade. A similar layer of large downward trends has also been observed in SAGE-II data but for the shorter period 1984-2000 and with a maximum downward trend of only $-4 \% /$ decade (World Meteorological Organization, 2003). This feature occurs between the potential temperature levels $380 \mathrm{~K}$ and $470 \mathrm{~K}$ in our data set (note that CATO is reconstructed on potential temperature levels). This corresponds to the "tropically controlled region" located between the tropical tropopause and the lower edge of the tropical pipe (Plumb, 1996) in which substantial exchange between tropics and extratropics occurs (Rosenlof et al., 1997). In EESC (panel b) there is no distinct maximum at $30^{\circ}$ but rather a smooth transition from high values in the extratropics to lowest values at the equator. This would be consistent with extratropical air depleted in ozone being mixed into the tropics. Above $450 \mathrm{~K}$ exchange between tropics and extratropics is strongly reduced (Plumb, 1996) which may explain the limited vertical extent of this feature.

Trends in the upper stratosphere (around $2 \mathrm{hPa}$ ) are underestimated in this version of CATO due to relaxation towards a climatology. Figure 10 therefore shows the trend based on the combined CATO/SBUV data set. In this figure a distinct second maximum in negative trends is seen in the upper stratosphere above the $10 \mathrm{hPa}$ level (above approx. $30 \mathrm{~km}$ ), in agreement with previous analyzes of SAGE, SBUV and Umkehr data (Randel et al., 1999; Zanis et al., 2006). Note that in terms of relative changes (\%/decade) the values would actually increase towards the top of the domain $(40 \mathrm{~km})$ reaching values of about $5-6 \%$ between $40^{\circ}$ and $60^{\circ}$ in the southern and somewhat further poleward in the northern hemisphere. The decrease in trends towards the poles at high altitudes is probably an artefact of the reconstruc- 
(a) $\mathrm{EESC}+\mathrm{QBO}+\mathrm{SF}$

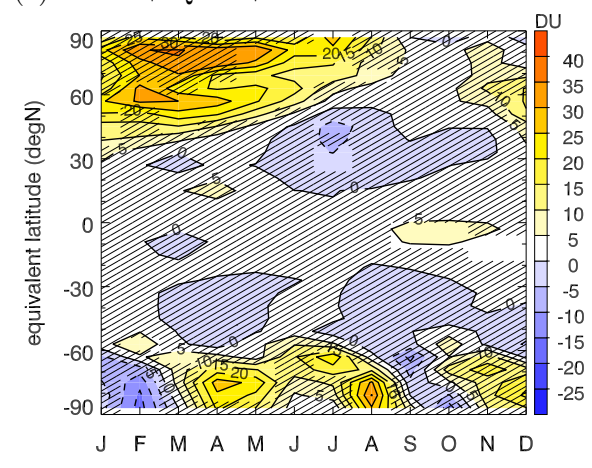

(c) $\mathrm{EESC}+\mathrm{QBO}+\mathrm{SF}+\mathrm{AERO}+\mathrm{EPFLUX}$

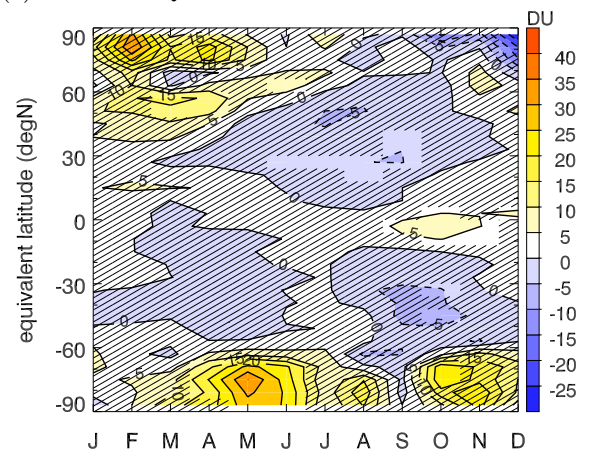

(b) $\mathrm{EESC}+\mathrm{QBO}+\mathrm{SF}+\mathrm{AERO}$

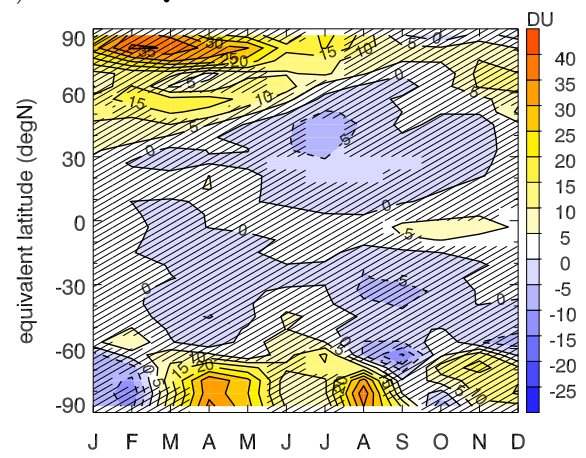

(d) Linear trend + $\mathrm{QBO}+\mathrm{SF}+\mathrm{AERO}+$ EPFLUX

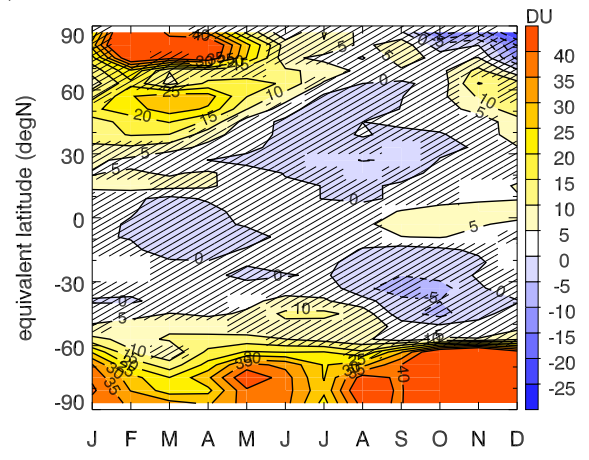

Fig. 11. Mean of total ozone residuals 1996-2004 for different model versions fitted to period January 1979 to December 1995 . (a) Model including the effects of EESC, QBO and solar cycle only. (b) Same as (a) but including the effect of volcanic eruptions. (c) Same as (b) but including effect of Eliassen-Palm flux. (d) Same as (c) but fitting a linear trend instead of EESC.

tion method used for this data set. SBUV data were assimilated in geographical coordinates and hence significant parts of the year are not covered by observations at high latitudes, in which case the CATO data set was relaxed towards a climatology.

\subsection{Ozone changes since 1996}

Recent studies have suggested that first stages of ozone recovery due to the phase-out of the production of ODSs can already be detected (Newchurch et al., 2003; Reinsel et al., 2005). However, some questions remain whether all natural influence factors such as solar cycle (Steinbrecht et al., 2004) or planetary wave driving (Dhomse et al., 2006) were properly accounted for in these studies. Here we follow a similar approach as Newchurch et al. (2003) to analyze the deviation of ozone from an expected behavior. For this purpose we fitted the regression model to the reference period January 1979 to December 1995 only but analyzed the residuals (measurements minus statistical model prediction) for the full period out to December 2004. As expected, the residuals average close to zero for the reference period over which the model was fitted. If, however, ozone increased faster (slower) than predicted in the following years then the mean $R$ of the residuals for January 1996 to December 2004 will be positive (negative). Using 1996 as reference year is in line with the study of Reinsel et al. (2005) and is motivated by the fact that this roughly corresponds to the time when EESC started to deviate significantly from the linear increase observed before.

Computing $R$ is equivalent to calculating the cumulative sum (CUSUM) of the residuals as done by Newchurch et al. (2003). In their Appendix they provided a formula for the variance VAR(CUSUM) which is composed of three terms representing the variance of the residuals up to 1996, the uncertainty in the mean level of the model fit, and the uncertainty in the trend estimated for the reference period. Because $R=1 / n_{2}$. CUSUM, where $n_{2}$ is the number of months between January 1996 and December 2004, the variance of $R$ is given by $\operatorname{VAR}(R)=1 / n_{2}^{2}$. $\operatorname{VAR}$ (CUSUM). We used this relation to estimate the $95 \%$ confidence level $(|R|>2 \sqrt{\operatorname{VAR}(R)})$.

$R$ was calculated for different versions of the model in order to illustrate the effect of adding a specific explanatory variable. Values of $R$ are displayed in Fig. 11 for total ozone as a function of month and equivalent latitude and in Fig. 12 for vertical cross-sections of ozone partial pressures. The dif- 
(a) $\mathrm{EESC}+\mathrm{QBO}+\mathrm{SF}$

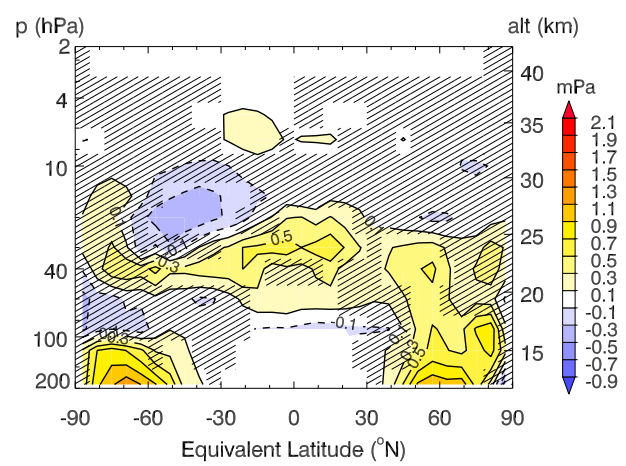

(c) $\mathrm{EESC}+\mathrm{QBO}+\mathrm{SF}+\mathrm{AERO}+\mathrm{EPFLUX}$

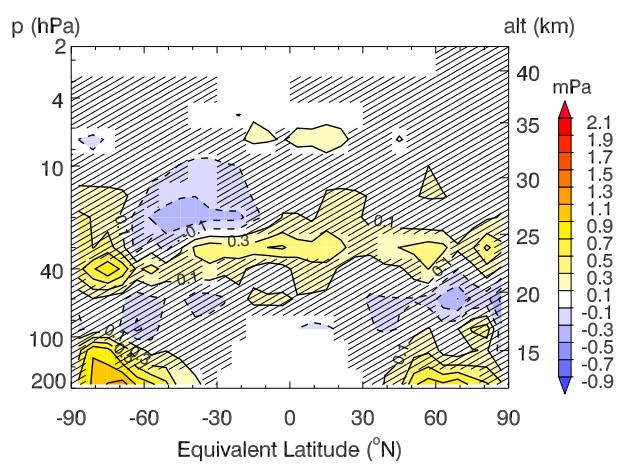

(b) $\mathrm{EESC}+\mathrm{QBO}+\mathrm{SF}+\mathrm{AERO}$

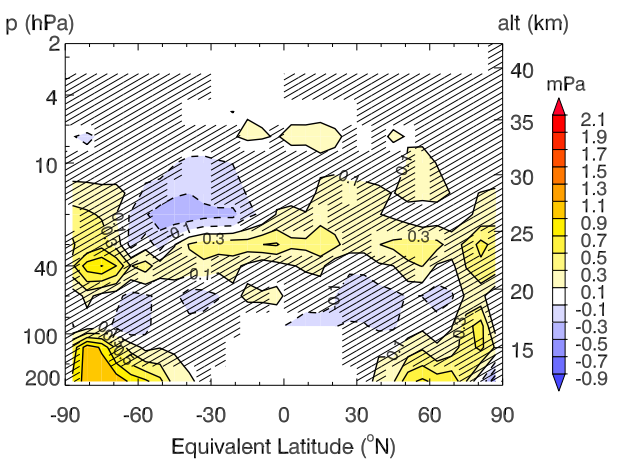

(d) Linear trend $+\mathrm{QBO}+\mathrm{SF}+\mathrm{AERO}+$ EPFLUX

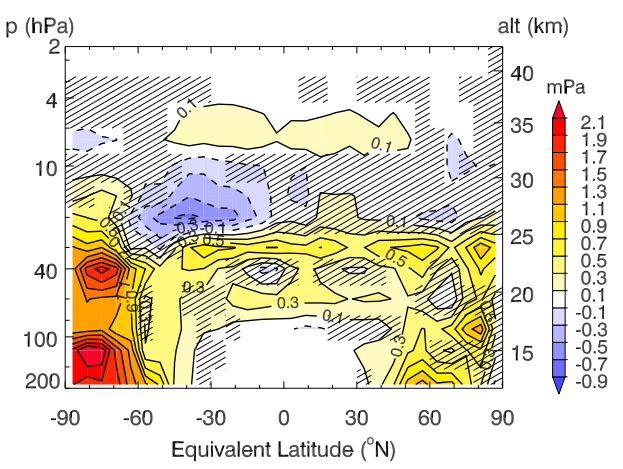

Fig. 12. Vertical cross-section of the mean ozone partial pressure residuals 1996-2004 for different model versions fitted to period January 1979 to December 1995. (a) Model including the effects of EESC, QBO and solar cycle only. (b) Same as (a) but including the effect of volcanic eruptions. (c) Same as b) but including effect of Eliassen-Palm flux. (d) Same as (c) but fitting a linear trend instead of EESC.

ferent panels show the results for a model including EESC, QBO and solar cycle only (a), adding the effects of volcanic eruptions (b), and adding the effects of EP-flux (c). Panel (d) is for the same model as in (c) except that EESC has been replaced by a linear trend.

When only EESC, QBO and solar flux (SF) are included in the model, values of $R$ are significantly positive in the $\mathrm{NH}$ mid- to high latitudes, in particular between winter and early summer (Fig. 11a), suggesting that ozone after 1996 was higher than expected from these classical proxies alone. Adding the effect of volcanic aerosols (b) reduces $R$ substantially in mid-latitudes (and to some extent also in the tropics) leaving only few areas of significantly positive values. The reason for this is that when leaving out the effect of aerosols the model attributes too much of the decrease between 1979 and 1995 to EESC resulting in mostly positive residuals after 1993 when the effect of Pinatubo slowly dissipated. This cannot be fully compensated by the too large increase in model ozone attributed to the increase in EESC after its peak in 1997. Adding EP flux (c) reduces the values of $R$ even further, not only in middle but also at polar latitudes. Hence, changes in wave forcing appear to have contributed to the observed increase in ozone since 1996, in agreement with results presented by Dhomse et al. (2006). However, springtime total ozone is still on average 5 to $10 \mathrm{DU}$ higher than expected between 1996 and 2004 even in the full model, a phenomenon yet unexplained (adding VPSC does not change this).

The situation is somewhat different in the SH. Mid-latitude ozone more or less evolved as expected since 1996. Neither aerosols nor EP flux made a large contribution to the tendency which was dominated by EESC. Significant positive and unexplained deviations are however observed at polar latitudes, especially in autumn (April and May) where the performance of the regression model is generally poor (see Fig. 3a). Springtime values have been recovering from decreasing ODSs somewhat faster than expected. However, it should again be noted that a model linear in EESC is problematic over Antarctica due to saturation in polar ozone depletion as already cautioned in Sect. 3.2.

Figure 11d finally shows the same results as panel (c) when a linear trend is used instead of EESC. Values of $R$ become significantly positive in this case at both middle and high latitudes in both hemispheres suggesting that this model is much less capable of explaining the recent ozone changes. This may be interpreted as a clear sign for the first stage 
(a) $\mathrm{QBO}+\mathrm{SF}$

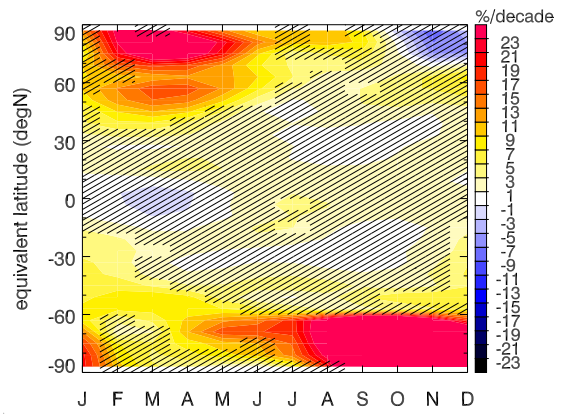

(d) $\mathrm{QBO}+\mathrm{SF}$

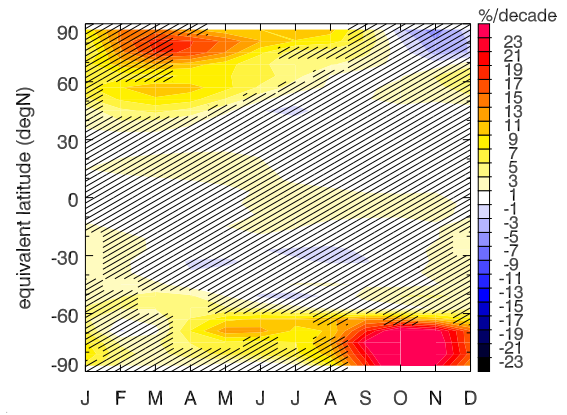

(b) $\mathrm{QBO}+\mathrm{SF}+\mathrm{AERO}$

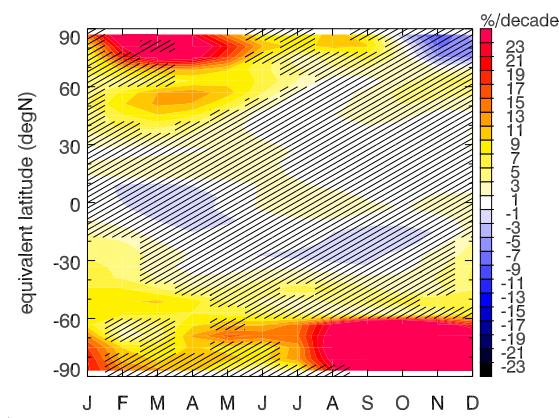

(e) $\mathrm{QBO}+\mathrm{SF}+\mathrm{AERO}$

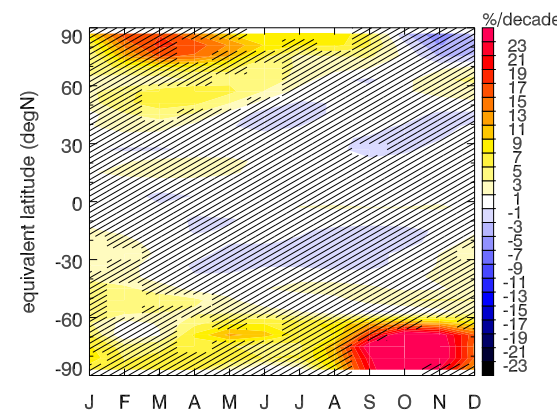

(c) $\mathrm{QBO}+\mathrm{SF}+\mathrm{AERO}+\mathrm{EPFLUX}$

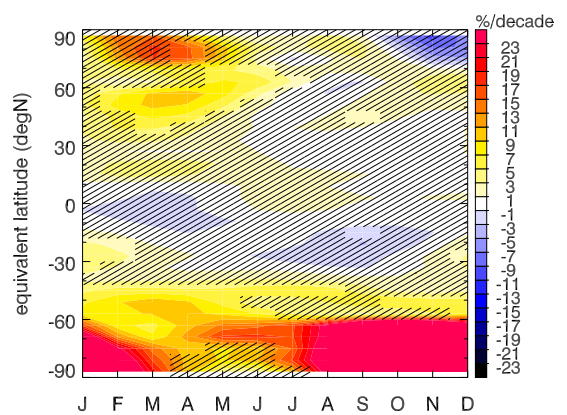

(f) $\mathrm{QBO}+\mathrm{SF}+\mathrm{AERO}+\mathrm{EPFLUX}$

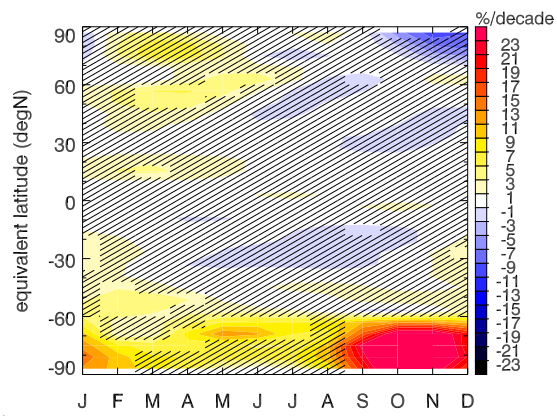

Fig. 13. Results of hockey-stick analysis with two different trends before and after December 1995. Top row: Change in trend (coeff. $\left.b_{1}\right)$ for period 1996-2004 as compared to period 1979-1995. Bottom row: Absolute trend $\left(b_{1}+b_{2}\right)$ for period 1996-2004.

of ozone recovery, i.e. for a significant deviation of the recent trend from the previous negative trend, which is attributable to changes in ODSs. An analysis of the change in trends based on the hockey-stick method (Weatherhead et al., 2000; Reinsel et al., 2005) supports this argument (see Appendix A).

The vertical distribution of ozone partial pressure residuals from 1996 to 2004 is shown in Fig. 12. It is fully consistent with the picture obtained for total ozone. Adding volcanic aerosols has a large effect on the results in the NH lower stratosphere and some effect on the tropical stratosphere. Adding EP-flux further reduces the values of $R$ especially at high northern latitudes. Comparing panels (d) and (c) again demonstrates that large positive residuals remain when we assume a continuation of the negative trend observed between 1979 and 1995, whereas the model using EESC successfully predicts the behavior of ozone after 1996 leaving only few areas of $R$ values significantly different from zero.

\section{Conclusions}

A multiple linear regression model has been applied to the 26 year long quasi three-dimensional ozone data set CATO to study the influence of the most significant processes on stratospheric ozone including QBO, solar cycle, volcanic eruptions, Brewer-Dobson circulation and polar ozone depletion. The CATO reconstruction method (Brunner et al., 2006) makes use of meteorological information from the ERA-40 reanalysis including stratospheric temperature and potential vorticity fields but not of vertical winds which are considered to be problematic. Long-term trends in CATO are sensitive to possible inaccuracies of temperature trends in ERA-40 which, however, are considered to be of high quality in the lower stratosphere, which is the focal region of this study. The use of equivalent latitude and potential temperature coordinates $\left(\phi_{E}, \theta\right)$ makes the CATO data set insensitive to short-term fluctuations caused by planetary waves which otherwise dominate the variability in total ozone at a given geographical location (Wohltmann et al., 2005). We adopted the process oriented approach presented by Wohltmann et al. (2006) ${ }^{1}$ in which the effects of various climate modes are implicitly but not explicitly included in the regression model. Climate fluctuations associated for instance with NAO may modify the position of troughs and ridges of planetary waves and influence the Brewer-Dobson circulation. These effects are largely accounted for by including EP flux as a proxy for the wave forcing of the stratospheric circulation and by using the $\left(\phi_{E}, \theta\right)$ framework. The extension of ozone satellite records out to 2004 allows for a better separation between the effects of the solar cycle, aerosols and the QBO because 
the latest solar cycle did not occur synchronously with a major volcanic disturbance and the QBO had a different phase relation than during the previous two cycles.

The QBO was found to have a large influence on ozone variability throughout the stratosphere. Volcanic eruptions (mainly Pinatubo) resulted in negative ozone anomalies in the extratropical lower stratosphere below $25 \mathrm{~km}$ and weakly positive anomalies above. In the tropics the region of depleted ozone reaches somewhat higher up. The largest effects in terms of percentage ozone changes were found below $16 \mathrm{~km}$ around $60^{\circ}$ in both hemispheres. Above that level the effects are much more pronounced in the $\mathrm{NH}$. The solar cycle has a relatively minor positive effect on stratospheric ozone maximizing at about $20^{\circ}$ on both sides of the equator as well as over the poles. Our analysis, which is limited to altitudes below $40 \mathrm{~km}$, indicates a maximum effect between 28 and $32 \mathrm{~km}$ in the tropics and between about 25 and $38 \mathrm{~km}$ in the extratropics, which is lower than suggested by previous studies. Furthermore, we find no negative signal in the tropical lower stratosphere which probably was an artefact of the statistical analysis in previous studies (Lee and Smith, 2003). EP flux has a profound influence on the interannual variability of ozone. Enhanced wave forcing results in large positive anomalies poleward of $60^{\circ}$ and negative anomalies in the tropical and subtropical lower stratosphere. Polar stratospheric ozone depletion has only been analyzed for the northern hemisphere, where an up to $4 \%$ reduction in summertime mid-latitude total ozone was found following cold Arctic winters, most likely as a result of dilution with air from the vortex.

Long-term trends are much less negative for the period 1979 to 2004 compared to 1979 to 1995 suggesting a levelling off during the recent years. Fitting the model to the period 1979 to 1995 but analyzing the residuals out to 2004 shows that the ozone changes since 1996 can not be understood by assuming a persistent negative trend. A model using EESC instead of a linear trend, on the other hand, quite successfully explains the recent changes, at least when the effects of aerosols and of EP flux changes are accounted for. Even then, lower stratospheric ozone increases since 1996 were somewhat larger in the northern hemisphere during spring and over Antarctica during most of the year than we are presently able to explain.

\section{Appendix A}

\section{Hockey-stick analysis of trend since 1996}

As suggested by Reinsel et al. (2005) a hockey-stick approach can be used to detect a change in trend after a given reference date relative to the trend before. In this case two separate linear trend components $b_{1}(t)$ and $b_{2}(t)$ are included in the regression model which then reads as

$Y(t)=a+b_{1} \cdot t+b_{2} \cdot t_{96}+\sum_{j=1}^{N} c_{j} \cdot X_{j}(t)+\epsilon(t)$

where $t_{96}$ is a linear ramp function which is equal to zero before December 1995 and after that is equal to the number of months since December 1995. The coefficient $b_{1}$ thus represents the trend between 1979 and 1995, $b_{2}$ is the change from this trend, and $b_{1}+b_{2}$ is the absolute trend for the period 1996 to 2004. A positive value of $b_{2}$ thus only indicates a positive change but the absolute trend may still be negative if the previous trend $b_{1}$ was sufficiently negative. The changes in trend $\left(b_{2}\right)$ and absolute trends $\left(b_{1}+b_{2}\right)$ for 1996 to 2004 are shown in Fig. 13 for different versions of the model. Large and significant changes in trend (top panels) are seen at middle to high northern latitudes in spring (February May). Including the effects of aerosols (b) and EP flux (c) reduces the magnitude of the changes significantly. Absolute trends 1996 to 2004 (bottom panels) are mostly positive in the regions where the largest changes in trends are observed. However, including all explanatory variables (f) reduces the regions of significant absolute trends to the months March to July between $50^{\circ}$ and $60^{\circ} \mathrm{N}$. Large changes and positive absolute trends are also observed over Antarctica. In southern mid-latitudes the changes in trends are most significant between January and April when quite large negative trends were observed before 1995 (cf. Fig. 8a).

Acknowledgements. We would like to thank MeteoSwiss and the European Center for Medium Range Weather Forecasts (ECMWF) for granting access to the meteorological archive of ERA-40 and operational data. We are very grateful to H.-R. Kuensch for helping develop the methodology used to create CATO. This work has been supported by the European Community grant through the project CANDIDOZ under contract EVK2-CT-2001-00133. CATO is freely available (ASCII tables of monthly means or complete data set of daily fields in netCDF format) through the web page http://www.iac.ethz.ch/cato/ or upon request.

Edited by: M. Dameris

\section{References}

Appenzeller, C., Weiss, A. K., and Staehelin, J.: North Atlantic Oscillation modulates total ozone winter trends, Geophys. Res. Lett., 27, 1131-1134, 2000.

Bodeker, G. E., Scott, J. C., Kreher, K., and McKenzie, R. L.: Global ozone trends in potential vorticity coordinates using TOMS and GOME intercompared against the Dobson network: 1978-1998, J. Geophys. Res., 106, 23 029-23 042, 2001.

Bodeker, G. E., Shiona, H., and Eskes, H.: Indicators of Antarctic ozone depletion, Atm. Chem. Phys., 5, 2603-2615, 2005.

Bojkov, R. D., Bishop, L., and Fioletov, V. E.: Total ozone trends from quality-controlled ground-based data (1996-1994), J. Geophys. Res., 100, 25 867-25 876, 1995. 
Brasseur, G.: The response of the middle atmosphere to long-term and short-term solar variability: A two-dimensional model, J. Geophys. Res., 98, 23 079-23 090, 1993.

Brunner, D., Staehelin, J., Künsch, H. R., and Bodeker, G. E.: A Kalman filter reconstruction of the vertical ozone distribution in an equivalent latitude - potential temperature framework from TOMS/GOME/SBUV total ozone observations., J. Geophys. Res., 111, D12308, doi:10.1029/2005JD006279, 2006.

Chipperfield, M. P.: Multiannual simulations with a threedimensional chemical transport model, J. Geophys. Res., 104, 1781-1805, 1999.

Chipperfield, M. P., Kinnersley, J. S., and Zawodny, J.: A twodimensional model study of the QBO signal in SAGE II NO and $\mathrm{O}_{3}$, Geophys. Res. Lett., 21, 589-592, 1994.

Chipperfield, M. P., Feng, W., and Rex, M.: Arctic ozone loss and climate sensitivity: Updated three-dimensional model study, J. Geophys. Res., 32, L11813, doi:10.1029/2005GL022674, 2005.

Cochrane, D. and Orcutt, G. H.: Application of least squares regression to relationships containing autocorrelated error terms, J. Am. Stat. Assoc., 44, 32-61, 1949.

Crutzen, P. J.: The influence of nitrogen oxides in the atmospheric ozone content, Q. J. Roy. Meteorol. Soc., 96, 320-325, 1970.

Dhomse, S., Weber, M., Wohltmann, I., Rex, M., and Burrows, J. P.: On the possible causes of recent increases in northern hemispheric total ozone from a statistical analysis of satellite data from 1979 to 2003, Atm. Chem. Phys., 6, 1165-1180, 2006.

Dobson, G. B. M.: Forty year's research on atmospheric ozone at Oxford: A history, Appl. Opt., 7, 387-405, 1968.

Egorova, T., Rozanov, E., Manzini, E., Haberreiter, M., Schmutz, W., Zubov, V., and Peter, T.: Chemical and dynamical response to the 11-year variability of the solar irradiance simulated with a chemistry-climate model, Geophys. Res. Lett., 31, L06119, doi: 10.1029/2003GL019294, 2004.

Egorova, T., Rozanov, E., Zubov, V., Schmutz, W., and Peter, T.: Influence of solar 11-year variability on chemical composition of the stratosphere and mesosphere simulated with a chemistryclimate model, Adv. Space Res., 35, 451-457, 2005.

Farman, J. C., Gardiner, B. G., and Shanklin, J. D.: Large losses of total ozone in Antarctica reveal seasonal $\mathrm{ClO}_{\mathrm{x}} / \mathrm{NO}_{\mathrm{x}}$ interaction, Nature, 315, doi:10.1038/315207a0, 1985.

Fioletov, V. E. and Shepherd, T. G.: Seasonal persistence of midlatitude total ozone anomalies, Geophys. Res. Lett., 30, 1417, doi:10.1029/2002GL016739, 2003.

Fioletov, V. E. and Shepherd, T. G.: Summertime total ozone variations over middle and polar latitudes, Geophys. Res. Lett., 32, L04807, doi:10.1029/2004GL022080, 2005.

Fortuin, J. P. F. and Kelder, H.: An ozone climatology based on ozonesonde and satellite measurements, J. Geophys. Res., 103, 31 709-31 734, 1998.

Fusco, A. C. and Salby, M. L.: Interannual variations of total ozone and their relationship to variations of planetary wave activity, J. Clim., 12, 1619-1629, 1999.

Garcia, R. R. and Solomon, S.: A possible relationship between interannual variability in Antarctic ozone and the quasi-biennial oscillation, Geophys. Res. Lett., 14, 848-851, 1987.

Hadjinicolaou, P., Pyle, J. A., Chipperfield, M. P., and Kettleborough, J. A.: Effect of interannual meteorological variability on mid-latitude $\mathrm{O}_{3}$, Geophys. Res. Lett., 24, 2993-2996, 1997.

Hadjinicolaou, P., Jrrar, A., Pyle, J. A., and Bishop, L.: The dynam- ically driven long-term trend in stratospheric ozone over northern mid-latitudes, Q. J. Roy. Meteorol. Soc., 128, 1393-1412, 2002.

Herman, J. R. and Larko, D.: Low ozone amounts during $1992-$ 1993 from Nimbus 7 and Meteor 3 total ozone mapping spectrometers, J. Geophys. Res., 99, 3483-3496, 1994.

Hofmann, D. J., Oltmans, S. J., Komhyr, W. D., Harris, J. M., Lathrop, J. A., Langford, A. O., Deshler, T., Johnson, B. J., Torres, A., and Matthews, W. A.: Ozone loss in the lower stratosphere over the United States in 1992-1993: Evidence for heterogeneous chemistry on the Pinatubo aerosol, Geophys. Res. Lett., 21, 65-68, 1994.

Hood, L. L.: The solar cycle variation of total ozone: Dynamical forcing in the lower stratosphere, J. Geophys. Res., 102, 13551370, 1997.

Huang, T. Y. W. and Brasseur, G. P.: Effect of long-term solar variability in a two-dimensional interactive model of the middle atmosphere, J. Geophys. Res., 98, 20 413-20 427, 1993.

Jackman, C. H., Fleming, E. L., Chandra, S., Considine, D. B., and Rosenfield, J. E.: Past, present, and future modeled ozone trends with comparisons to observed trends, J. Geophys. Res., 101, 28 753-28767, 1996.

Jiang, Y., Yung, Y. L., and Zurek, R. W.: Decadal evolution of the Antarctic ozone hole, J. Geophys. Res., 101, 8985-9000, doi: 10.1029/96JD00063, 1996.

Johnston, H.: Reduction of stratospheric ozone by nitrogen oxide catalysts from supersonic transport exhausts, Science, 173, 517522, 1971.

Karpetchko, A., Kyroö, E., and Knudsen, B. M.: Arctic and Antarctic polar vortices 1957-2002 as seen from the ERA40 reanalyses, J. Geophys. Res., 110, D21109, doi:10.1029/ 2005JD006113, 2005.

Kinnison, D. E., Grant, K. E., Connell, P. S., Rotman, D. A., and Wuebbles, D. J.: The chemical and radiative effects of the Mount Pinatubo eruption, J. Geophys. Res., 99, 25 705-25 731, 1994.

Knudsen, B. M. and Groß, J.-U.: Northern mid-latitude stratospheric ozone dilution in spring modeled with simulated mixing, J. Geophys. Res., 105, 6885-6890, 2000.

Koch, G., Wernli, H., Staehelin, J., and Peter, T.: A Lagrangian analysis of stratospheric ozone variability and long-term trens above Payerne (Switzerland) during 1970-2001, J. Geophys. Res., 107, 4373, doi:10.1029/2001JD001550, 2002.

Kodera, K.: Influence of volcanic eruptions on the troposphere through stratospheric dynamical processes in the northern hemisphere winter, J. Geophys. Res., 99, 1273-1282, 1994.

Konopka, P., Groß, J.-U., Bausch, S., Müeller, R., McKenna, D. S., Morgenstern, O., and Orsolini, Y.: Dynamics and chemistry of vortex remnants in late Arctic spring 1997 and 2000: Simulations with the Chemical Lagrangian Model of the Stratosphere (CLaMS), Atmos. Chem. Phys., 3, 839-849, 2003, http://www.atmos-chem-phys.net/3/839/2003/.

Labitzke, K.: Sunspots, the QBO, and the stratospheric temperature in the north polar region, Geophys. Res. Lett., 14, 535-537, 1987.

Labitzke, K. and Kunze, M.: Stratospheric temperatures over the Arctic: Comparison of three data sets, Meteorol. Z., 14, 65-74, 2005.

Labitzke, K. and van Loon, H.: The QBO effect on the solar signal in the global stratosphere in the winter of the Northern Hemisphere, J. Atmos. Sol-Terr. Phys., 62, 621-628, 2000. 
Langematz, U., Grenfell, J. L., Matthes, K., Mieth, P., Kunze, M., Steil, B., and Brühl, C.: Chemical effects in 11-year solar cycle simulations with the Freie Universität Berlin Climate Middle Atmosphere Model with online chemistry (FUB-CMAM-CHEM), Geophys. Res. Lett., 32, L13803, doi:10.1029/2005GL022686, 2005.

Lee, H. and Smith, K.: Simulation of the combined effects of solar cycle, quasi-biennial oszillation, and volcanic forcing on stratospheric ozone changes in recent decades, J. Geophys. Res., 108, 4049, doi:10.1029/2001JD001503, 2003.

McCormack, J. P.: The influence of the 11-year solar cycle on the quasi-biennial oscillation, Geophys. Res. Lett., 30, 2162, doi:10. 1029/2003GL018314, 2003.

McCormack, J. P. and Hood, L. L.: Apparent solar cycle variations of upper stratospheric ozone and temperature: Latitude and seasonal dependencies, J. Geophys. Res., 101, 20 933-20 944, 1996.

McCormack, J. P., Hood, L. L., Nagatani, R., Miller, A. J., Planet, W. G., and McPeters, R. D.: Approximate separation of volcanic and 11-year signals in the SBUV-SBUV/2 total ozone record over the 1979-1995 period, Geophys. Res. Lett., 24, 2729-2732, 1997.

Molina, M. J. and Rowland, F. S.: Stratospheric sink for chlorofluoromethanes: Chlorine atom-catalysed destruction of ozone, Nature, 249, 810-812, 1974.

Newchurch, M. J., Yang, E.-S., Cunnold, D. M., Reinsel, G. C., Zawodny, J. M., and Russell III, J. M.: Evidence for slowdown in stratospheric ozone loss: First stage of ozone recovery, J. Geophys. Res., 108, 4507, doi:10.1029/2003JD003471, 2003.

Newman, P. A., Nash, E. R., Kawa, S. R., Montzka, S. A., and Schauffler, S. M.: When will the Antarctic ozone hole recover?, Geophys. Res. Lett., 33, L12814, doi:10.1029/2005GL025232, 2006.

Oltmans, S. J. and London, J.: The quasi-biennial oscillation in atmospheric ozone, J. Geophys. Res., 87, 8981-8989, 1982.

Plumb, R. A.: A "tropical pipe" model of stratospheric transport, J. Geophys. Res., 101, 3957-3972, 1996.

Randel, W. J. and Wu, F.: TOMS total ozone trends in potential vorticity coordinates, Geophys. Res. Lett., 22, 683-686, 1995.

Randel, W. J. and Wu, F.: Isolation of the ozone QBO in SAGE II data by singular-value decomposition, J. Atmos. Sci., 53, 25462559, 1996.

Randel, W. J. and Wu, F.: A stratospheric ozone trends data set for global modeling studies, Geophys. Res. Lett., 26, 3089-3092, 1999.

Randel, W. J., Stolarski, R. S., Cunnold, D. M., Logan, J. A., and Newchurch, M. J.: Trends in the vertical distribution of ozone, Science, 285, 1689-1692, 1999.

Randel, W. J., Wu, F., and Stolarski, R.: Changes in column ozone correlated with the stratospheric EP flux, J. Meteorol. Soc. Japan, 80, 849-862, 2002.

Randel, W. J., Udelhofen, P., Fleming, E., et al.: The SPARC intercomparison of middle-atmosphere climatologies, J. Climate, 17, 986-1003, 2005.

Reinsel, G. C., Weatherhead, E. C., Tiao, G. C., Miller, A. J., Nagatani, R. M., Wuebbles, D. J., and Flynn, L. E.: On detection of turnaround and recovery in trend for ozone, J. Geophys. Res., 107, 4078, doi:10.1029/2001JD000500, 2002.

Reinsel, G. C., Miller, A. J., Weatherhead, E. C., Flynn, L. E., Nagatani, R. M., Tiao, G. C., and Wuebbles, D. J.: Trend analysis of total ozone data for turnaround and dynamical contributions, J. Geophys. Res., 110, D16306, doi:10.1029/2004JD004662, 2005.

Rex, M., Salawitch, R. J., von der Gathen, P., Harris, N. R. P., Chipperfield, M. P., and Naujokat, B.: Arctic ozone loss and climate change, Geophys. Res. Lett., 32, L04116, doi:10.1029/ 2003GL018844, 2004.

Rind, D., Perlwitz, J., and Lonergan, P.: AO/NAO response to climate change: 1. Respective influences of stratospheric and tropospheric climate changes, J. Geophys. Res., 110, D12107, doi: 10.1029/2004JD005103, 2005.

Rosenfield, J. E., Considine, D. B., Meade, P. E., Bacmeister, J. T., Jackman, C. H., and Schoeberl, M. R.: Stratospheric effects of Mount Pinatubo aerosol studied with a coupled two-dimensional model, J. Geophys. Res., 102, 2649-3670, 1997.

Rosenlof, K. H., Tuck, A. F., Kelly, K. K., Russel, J. M., and McCormick, M. P.: Hemispheric asymmetries in water vapor and inferences about transport in the lower stratosphere, J. Geophys. Res., 102, 13213-13 234, 1997.

Salby, M. and Callaghan, P.: Connection between the solar cycle and the QBO: The missing link, J. Clim., 13, 2652-2662, 2000.

Salby, M., Callaghan, P., and Shea, D.: On the interdependence of the tropical and extratropical QBO and its relationship to the solar cycle, J. Geophys. Res., 102, 29 789-29798, 1997.

Salby, M. L. and Callaghan, P. F.: Interannual changes of the stratospheric circulation: Influence on the tropics and southern hemisphere, J. Clim., 17, 952-964, 2004.

Salby, M. L. and Callaghan, P. F.: Relationship of the quasi-biennial oscillation to the stratospheric signature of the solar cycle, J. Geophys. Res., 111, D06110, doi:10.1029/2005JD006012, 2006.

Santer, B. D., Wigley, T. M. L., Simmons, A. J., et al.: Identification of anthropogenic climate change using a secondgeneration analysis, J. Geophys. Res., 109, D21104, doi:10. 1029/2004JD005075, 2004.

Sato, M., Hansen, J., McCormack, M., and Pollack, J.: Stratospheric aerosol optical depth, J. Geophys. Res., 98, 1850-1890, 1993.

Schnadt, C. and Dameris, M.: Relationship between North Atlantic Oscillation changes and stratospheric ozone recovery in the Northern Hemisphere in a chemistry-climate model, J. Geophys. Res., 30, 1487, doi:10.1029/2003GL017006, 2003.

Schoeberl, M. R., Lait, L. R., Newman, P. A., Martin, R. L., Proffitt, M. H., Hartmann, D. L., Loewenstein, M., Podolske, J., Strahan, S. E., and Gary, B.: Reconstruction of the constituent distribution and trends in the Antarctic polar vortex from ER-2 flight observations, J. Geophys. Res., 94, 16 815-16845, 1989.

Solomon, S., Kiehl, J. T., Garcia, R. R., et al.: Tracer transport by the diabatic circulation deduced from satellite observations, J. Atmos. Sci., 43, 1603-1617, 1986.

Solomon, S., Portmann, R. W., Garcia, R. R., Thomason, L. W., Poole, L. R., and McCormick, M. P.: The role of aerosol variations in anthropogenic ozone depletion at northern mid-latitudes, J. Geophys. Res., 101, 6713-6728, 1996.

Staehelin, J., Harris, N. R. P., Appenzeller, C., Eberhard, J., and Piechowski, M.: Observations of ozone trends, Rev. Geophys., 39, 231-290, 2001.

Steinbrecht, W., Claude, H., Köhler, U., and Hoinka, K. P.: Correlation between tropopause height and total ozone: Implication for long-term trends, J. Geophys. Res., 103, 19 183-19 192, 1998.

Steinbrecht, W., Hassler, B., Claude, H., Winkler, P., and Stolarski, 
R. S.: Global distribution of total ozone and lower stratospheric temperature variations, Atm. Chem. Phys., 3, 1421-1438, 2003.

Steinbrecht, W., Claude, H., and Winkler, P.: Enhanced upper stratospheric ozone: Sign of recovery or solar cycle effect?, J. Geophys. Res., 109, D02308, doi:10.1029/2003JD004284, 2004.

Steinbrecht, W., Claude, H., Schönenborn, F., et al.: Long-term evolution of upper stratospheric ozone at selected stations of the Network for the Detection of Stratospheric Cchange (NDSC), J. Geophys. Res., 111, D10308, doi:10.1029/2005JD006454, 2006.

Stolarski, R. S. and Cicerone, R. J.: Stratospheric chlorine: A possible sink for ozone, Can. J. Chem., 52, 1610-1615, 1974.

Stolarski, R. S., Bloomfield, P., McPeters, R. D., and Herman, J. R.: Total ozone trends deduced from Nimbus 7 TOMS data, Geophys. Res. Lett., 18, 1015-1018, 1991.

Thomason, L. W. and Peter, T.: The Assessment of stratospheric aerosol properties, SPARC Newsletter 26, SPARC, Toronto, ON, Canada, 2006.

Trepte, C. R., Viega, R. E., and McCormick, M. P.: The poleward dispersal of the Mount Pinatubo volcanic aerosol, J. Geophys. Res., 98, 18 563-18 573, 1993.

Uppala, S. M., Kallberg, P. W., Simmons, A. J., et al.: The ERA40 re-analysis, Q. J. Roy. Meteorol. Soc., 131, 2961-3012, doi: 10.1256/qj.04.176, 2005.

van Loon, H. and Labitzke, K.: The 10-12 year atmospheric oscillation, Meteorol. Z., 3, 259-266, 1994.

Viereck, R. A., Puga, L. C., Judge, D., Weber, M., and Tobiska, W. K.: The Mg II index: A proxy for solar EUV, Geophys. Res. Lett., 28, 1343-1346, 2001

Wang, H. J., Cunnold, D. M., and Bao, X.: A critical assessment of Stratospheric Aerosol Gas Experiment ozone trends, J. Geophys. Res., 101, 12 495-12 514, 1996.

Wang, H. J., Cunnold, D. M., Thomason, L. W. T., Zawodny, J. M., Joseph, M., and Bodeker, G. E.: Assessment of SAGE V6.1 ozone data quality, J. Geophys. Res., 107, 4691, doi:10.1029/ 2002JD002418, 2002.

Weatherhead, E. C. and Andersen, S. B.: The search for signs of recovery of the ozone layer, Nature, 441, 39-45, doi:10.1038/ nature04746, 2006.
Weatherhead, E. C., Reinsel, G. C., Tiao, G. C., Jackman, C. H., Bishop, L., Frith, S. M. H., DeLuisi, J., Keller, T., Oltmans, S., Fleming, E., Wuebbles, D., Kerr, J., Miller, A., Herman, J., McPeters, R., Nagatani, R., and Frederick, J.: Detecting the recovery of total column ozone, J. Geophys. Res., 105, $22201-$ $22210,2000$.

Weiss, A. K., Staehelin, J., Appenzeller, C., and Harris, N. R. P.: Chemical and dynamical contributions to ozone profile trends of the Payerne (Switzerland) balloon soundings, J. Geophys. Res., 106, 22 685-22 694, 2001.

Wohltmann, I., Rex, M., Brunner, D., and Mäder, J.: Integrated equivalent latitude as a proxy for dynamical changes in ozone column, Geophys. Res. Lett., 32, L09811, doi:10.1029/ 2005GL022497, 2005.

World Meteorological Organization: Scientific assessment of ozone depletion: 1994, Global Ozone Research and Monitoring Project, Geneva, Switzerland, report No. 37, 1995.

World Meteorological Organization: Scientific assessment of ozone depletion: 2002, Global Ozone Research and Monitoring Project, Geneva, Switzerland, report No. 47, 2003.

Yang, H. and Tung, K. K.: Statistical significance and pattern of extratropical QBO in column ozone, Geophys. Res. Lett., 21, 2235-2238, 1994.

Yang, H. and Tung, K. K.: On the phase propagation of extratropical ozone quasi-biennial oscillation in observational data, J. Geophys. Res., 100, 9091-9100, 1995.

Zanis, P., Maillard, E., Staehelin, J., Zerefos, C., Kosmidis, E., Tourpali, K., and Wohltmann, I.: On the turnaround of stratospheric ozone trends deduced from the re-evaluated Umkehr record of Arosa, Switzerland, J. Geophys. Res., in press, 2006.

Zerefos, C. S., Tourpali, K., and Balis, D.: Solar activity-ozone relationships in the vertical distribution of ozone, Int. J. Remote Sens., 26, 3449-3454, 2005.

Zhao, X., Turco, R. P., Kao, C.-Y. J., and Elliot, S.: Aerosolinduced chemical perturbations of stratospheric ozone: Threedimensional simulations and analysis of mechanisms, J. Geophys. Res., 102, 3617-3637, 1997.

Ziemke, J. R., Chandra, S., McPeters, R. D., and Newman, P. A.: Dynamical proxies of column ozone with application to global trend models, J. Geophys. Res., 102, 6117-6129, 1997. 